The official journal of

INTERNATIONAL FEDERATION OF PIGMENT CELL SOCIETIES · SOCIETY FOR MELANOMA RESEARCH

\title{
PIGMENT CELL \& MELANOMA
}

\section{Research}

Plasticity for colour adaptation in vertebrates

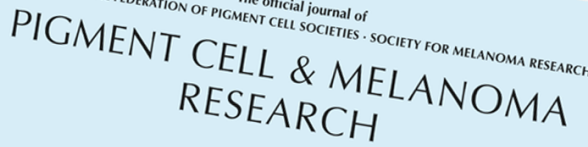
explained by the evolution of the genes pomc, pmch and pmchl

Gabriel E. Bertolesi | John Zhijia Zhang | Sarah McFarlane

\section{DOI: 10.1111/pcmr.12776}

\section{Volume 32, Issue 4, Pages 510-527}

If you wish to order reprints of this article,

please see the guidelines here

Supporting Information for this article is freely available here

\section{EMAIL ALERTS}

Receive free email alerts and stay up-to-date on what is published in Pigment Cell \& Melanoma Research - click here

Submit your next paper to PCMR online at http://mc.manuscriptcentral.com/pcmr

Subscribe to PCMR and stay up-to-date with the only journal committed to publishing basic research in melanoma and pigment cell biology

As a member of the IFPCS or the SMR you automatically get online access to PCMR. Sign up as a member today at www.ifpcs.org or at www.societymelanomaresarch.org 


\title{
Plasticity for colour adaptation in vertebrates explained by the evolution of the genes pomc, pmch and pmchl
}

\author{
Gabriel E. Bertolesi (iD | John Zhijia Zhang | Sarah McFarlane
}

Department of Cell Biology and Anatomy, Hotchkiss Brain Institute, Alberta Children's Hospital Research Institute, Cumming School of Medicine, University of Calgary, Calgary, Alberta, Canada

\section{Correspondence}

Gabriel E. Bertolesi, Department of Cell Biology and Anatomy, Hotchkiss Brain Institute, Alberta Children's Hospital Research Institute, Cumming School of Medicine, University of Calgary, Calgary, AB, Canada.

Email: gbertole@ucalgary.ca

Funding information

Natural Sciences and Engineering Research Council of Canada

\begin{abstract}
Different camouflages work best with some background matching colour. Our understanding of the evolution of skin colour is based mainly on the genetics of pigmentation ("background matching"), with little known about the evolution of the neuroendocrine systems that facilitate "background adaptation" through colour phenotypic plasticity. To address the latter, we studied the evolution in vertebrates of three genes, pomc, pmch and pmchl, that code for $\alpha-\mathrm{MSH}$ and two melanin-concentrating hormones ( $\mathrm{MCH}$ and $\mathrm{MCHL}$ ). These hormones induce either dispersion/aggregation or the synthesis of pigments. We find that $\alpha-\mathrm{MSH}$ is highly conserved during evolution, as is its role in dispersing/synthesizing pigments. Also conserved is the three-exon pmch gene that encodes $\mathrm{MCH}$, which participates in feeding behaviours. In contrast, pmchl (known previously as pmch), is a teleost-specific intron-less gene. Our data indicate that in zebrafish, pmchl-expressing neurons extend axons to the pituitary, supportive of an MCHL hormonal role, whereas zebrafish and Xenopus pmch+ neurons send axons dorsally in the brain. The evolution of these genes and acquisition of hormonal status for MCHL explain different mechanisms used by vertebrates to background-adapt.
\end{abstract}

\section{KEYWORDS}

camouflage, chromatophore, feeding, hormone, $\mathrm{MCH} 1, \mathrm{MCH} 2$, melanin-concentrating hormone, melanocyte, neuron, pigmentation

\section{$1 \mid$ INTRODUCTION}

Different types of camouflage (i.e., masquerade, disruptive and distractive coloration, surface disruption and countershading) are generated by a combination of skin patterns and colours selected through evolution in many prey and predator species as a means to reduce the likelihood of detection (crypsis) (Skelhorn \& Rowe, 2016). In general, they are not mutually exclusive and work best when several of their components match the background colour (Eterovick et al., 2018). The matching of skin pigmentation to background colour can be genetically determined (defined here as "background matching"), or induced by physiological plasticity through differential secretion of hormones by neuroendocrine systems ("background adaptation") (Baker \& Bird, 2002; Hoekstra, 2006). An example of genetically based background matching are mutations that produced a hyperactive melanocortin 1 receptor (Mc1r), the main receptor for $\alpha$-melanocyte-stimulating hormone ( $\alpha$-MSH) (Robbins et al., 1993). The emergence of genetic polymorphisms in Mc1r expressed by pigment cells, and the selection of standing genetic variations, resulted in adaptive evolution of background matching in populations of reptiles, birds and mammals (Linnen et al., 2013; Price \& Bontrager, 2001; Rosenblum, Hoekstra, \& Nachman, 2004). In contrast, background adaptation is plastic, with colour change mediated by pigment cell receptors activated by hormones secreted after eye photoperception of surface colour. Although background adaptation occurs in many species, differences exist in the mechanisms between species that are not well understood. Here, the evolutionary analysis of three critical genes involved in background 
adaptation, proopiomelanocortin (pomc) and pro-melanin-concentrating hormone genes ( $p m c h$ and pmchl-"like" ( $p c m h l)$ ) that encode for $\alpha$ $\mathrm{MSH}$ and two melanin-concentrating hormones ( $\mathrm{MCH}$ and $\mathrm{MCHL}$ ), respectively, provides an explanation for these differences.

Background adaptation is mediated by the secretion into the circulation of two hormones, $\alpha-\mathrm{MSH}$ and $\mathrm{MCH}$ (Figure 1). These hormones interact with specific receptors expressed by skin pigment cells to trigger the dispersion/aggregation of intracellular pigments (secretion of pigments in mammals and birds), or the synthesis of specific pigment types (e.g., eumelanin or pheomelanin), which define skin colour. $\alpha-\mathrm{MSH}$ and $\mathrm{MCH}$ form the basis of two current theories that explain background adaptation in vertebrates: (a) a "dual-hormonal theory" in teleosts, with $\alpha-\mathrm{MSH}$ and $\mathrm{MCH}$ (we rename here $\mathrm{MCHL}$ ) darkening and lightening the skin, respectively, and (b) a uni-hormonal system in tetrapods, in which plasma $\alpha-\mathrm{MSH}$ levels regulate background adaptation (Kawauchi, 2006). During evolution, however, the capacity of $\alpha-\mathrm{MSH}$ and $\mathrm{MCH}$ to act as hormones and/or to interact with skin pigment cells changed, as did their roles in background adaptation. For example, skin melanophores in species from early phylogenetic lineages, before the appearance of holosteans, do not respond to MCH (Baker \& Bird, 2002; Sherbrooke \& Hadley, 1988), while in more recent lineages, for instance amphibian and reptilian tetrapods, $\mathrm{MCH}$ either has no effect or triggers pigment dispersion (Ferroni \& Castrucci, 1987; Wilkes, Hruby, Castrucci, Sherbrooke, \& Hadley, 1984). Moreover, while an $\mathrm{MCH}$ is released into the bloodstream in teleosts, this does not appear to be the case for $\mathrm{MCH}$ in other taxa (i.e., sharks [Chondrichthyes], amphibians, birds and mammals [Tetrapodas]), where it may not act as a hormone (Baker \& Bird, 2002; Cardot, Fellmann, \& Bugnon,

\section{Significance}

The secretion into the circulation of two hormones, $\alpha-\mathrm{MSH}$ and $\mathrm{MCH}$ (renamed here as $\mathrm{MCHL}$ ), forms the basis of two theories that explain the different mechanisms vertebrates use to background-adapt: (a) a "dual-hormonal theory" in teleosts, with $\alpha-\mathrm{MSH}$ and MCHL darkening and lightening the skin, respectively; and (b) a uni-humoral system in tetrapods, in which $\alpha-\mathrm{MSH}$ regulates the response. Here, we show that MCHL possesses "hormonal status" via neurons that extend axons to the neurohypophysis, while $\mathrm{MCH}$ does not. pmchl is a teleost-specific gene that encodes a highly similar but not identical peptide to $\mathrm{MCH}$.

1994; Cardot, Griffond, Risold, Blähser, \& Fellmann, 1999; Lázár, Maderdrut, \& Merchenthaler, 2002; Mizusawa et al., 2012).

$\alpha-\mathrm{MSH}$ is the hypophyseal hormone secreted from the pars intermedia pituitary into the circulation that mediates the background adaptation described initially in amphibians (Babák, 1910), and then in reptiles and some teleosts (Baker, Wilson, \& Bowley, 1984; Okelo, 1986). $\alpha-\mathrm{MSH}$ is a 13 -amino acid (a.a.) peptide generated by the cleavage of the amino terminus of the adrenocorticotropic hormone (ACTH) peptide, which itself is processed from a larger precursor, proopiomelanocortin (POMC) (Dores, Liang, Davis, Thomas, \& Petko, 2016; Liang, Reinick, Angleson, \& Dores, 2013) (Figure 1). $\alpha$ $\mathrm{MSH}$ induces pigment dispersion to darken the skin, and both pomc mRNA in the pars intermedia pituitary and plasma levels of $\alpha-\mathrm{MSH}$

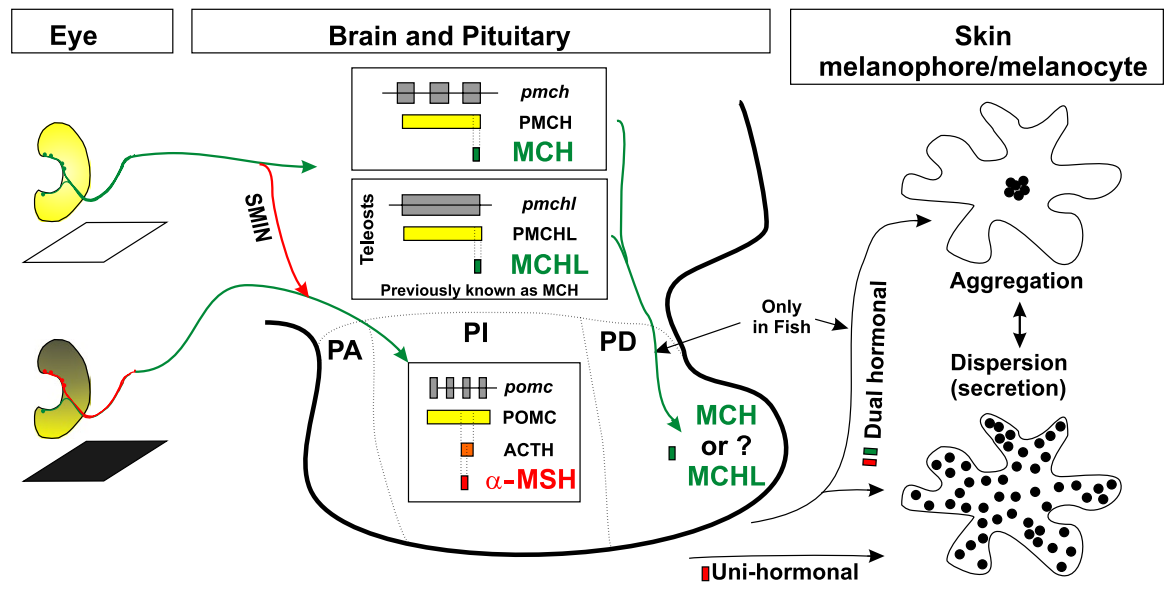

FIG URE 1 Schematic representation of the regulation of background adaptation by MCH, MCHL and $\alpha-M S H$. In amphibians (possibly in Tetrapoda), a uni-hormonal mechanism regulates background adaptation. With a black background, pomc mRNA levels increase in the pars intermedia (PI) pituitary, and the prehormone is processed to ACTH and then to $\alpha$-MSH. Plasma levels of $\alpha$-MSH increase and induce melanosome dispersion (secretion in mammals and birds) to darken the skin. With a white background, superchiasmatic melanotrope inhibitory neurons (SMIN) are active and repress pituitary melanotropes to decrease the levels of $\alpha$-MSH. SMIN neurons are described only in amphibians (reviewed by Bertolesi \& McFarlane, 2018). An additional mechanism exists in certain fish, in that adaptation to a white background increases the expression of $\mathrm{PMCH} / \mathrm{PMCHL}$ in brain neurons (dual-hormonal mechanism). Two genes exist in fish, a three-exon ( $p m c h)$ gene (grey rectangles) conserved in vertebrates and a single-exon ( $p m c h l$ ) gene (single grey rectangle; teleost). $\mathrm{MCH}$ and $\mathrm{MCHL}$ are processed from the carboxy-end of the prehormones $\mathrm{PMCH}$ and $\mathrm{PMCHL}$, respectively. The data herein indicate that it is $\mathrm{MCHL}$ that functions in background adaptation. Neurons expressing pmchl project their axons to the pars distalis (PD) of the pituitary, and the peptide is secreted into the bloodstream, giving "hormonal status" to MCHL. MCHL interacts with specific receptors located in skin melanophores to induce melanosome aggregation and lighten the skin. PA, pars anterior; PD, pars distalis 
increase in organisms with a black background (Baker et al., 1984; de Rijk, Jenks, \& Wendelaar Bonga, 1990; Jenks, Overbeeke, \& McStay, 1977).

The existence of a second hormone secreted from the pars nervosa of the pituitary, with opposite effects on background adaptation to $\alpha-\mathrm{MSH}$, was suggested initially by Hogben and Slome (1936) in their "dual-hormonal control" theory. $\mathrm{MCH}$ is processed from the C-terminal end of the preprohormone PMCH (Figure 1). In fish, an
"MCH" peptide is produced in the hypothalamus and transported down axons to be secreted from the neurohypophysis upon stimulation (Baker \& Bird, 2002; Enami, 1955; Kawauchi, 2006; Kawauchi, Kawazoe, Tsubokawa, Kishida, \& Baker, 1983) (Figure 1). The ability to adapt to a white background by aggregating melanosomes asso-

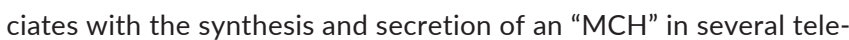
ost species (Gröneveld, Balm, Martens, \& Wendelaar Bonga, 1995a; Kishida, Baker, \& Eberle, 1989; Mizusawa et al., 2012; Sugimoto,

(a)
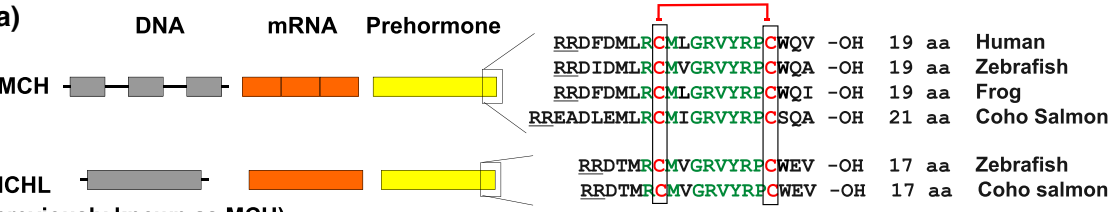

(previously known as $\mathrm{MCH}$ )

(b)

Danio rerio (Zebrafish)
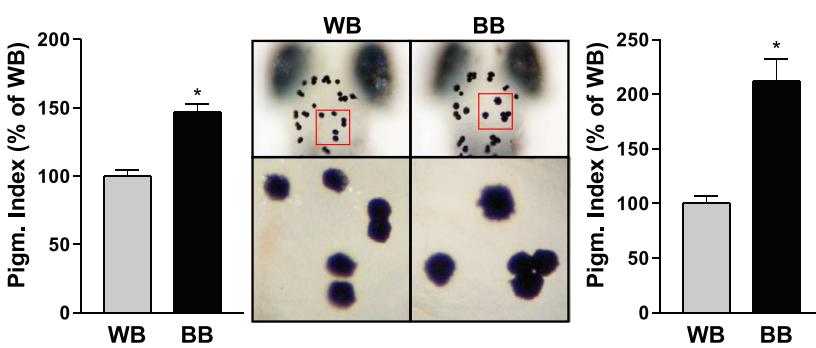

Xenopus laevis (Frog tadpoles)

(c)
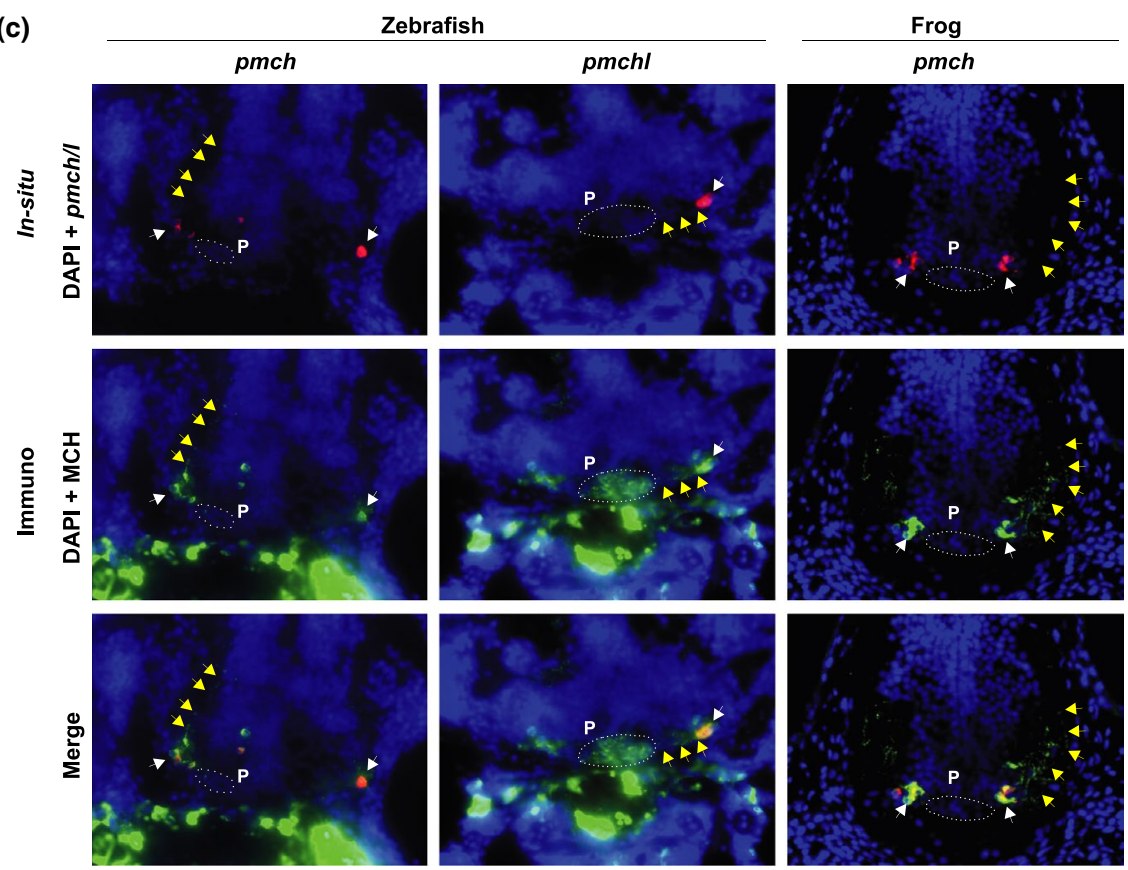

FIGURE 2 Zebrafish and Xenopus both background-adapt but only in zebrafish do MCHL+ neurons project axons to the pituitary. (a) Schematic of the genomic structure of the three-exon pmch and one-exon pmchl genes, the mRNAs, the prehormones and the aligned a.a. sequence of $\mathrm{MCH}$ and $\mathrm{MCHL}$. The two cysteines involved in the disulphide bonds in $\mathrm{MCH}$ and $\mathrm{MCHL}$ are indicated in red, and a.a. identity in green, while the predicted dibasic peptide at the cleavage site (RR) is underlined. (b) Quantification of the pigmentation index (left) and dorsal pictures of the head (right) from zebrafish and frog larvae developed for 5 days with a white (WB) or a black (BB) background. Bars indicate average (normalized to WB) from two independent experiments ( $n=10 ; N=2 ; \pm S E ;{ }^{*} p<0.05$, ANOVA). Bottom right panels are enlargements of the red squares. (c) FISH against pmch and pmchl followed by immunohistochemistry against MCH/MCHL. Transverse brain sections $(12 \mu \mathrm{m})$ processed for FISH (red; white arrows) and with a polyclonal anti-human $\mathrm{MCH}$ antibody (green) that recognizes both $\mathrm{MCH}$ and $\mathrm{MCHL}$. Note $\mathrm{MCH}$ immunoreactivity surrounding the pituitary $(\mathrm{P})$ in zebrafish but not Xenopus. pmchl+ neurons project their axons to the pituitary in fish (yellow arrows), while the axons of pmch+ neurons from both species project dorsally and are restricted to the brain (hypothalamus areas) 
Nagamori, Yasui, \& Oshima, 1997). Thus, a dual-hormonal control of regulation by $\alpha-\mathrm{MSH}$ and an $\mathrm{MCH}$ with "hormonal status" may exist in fish. $\mathrm{MCH}$ can also act as a neurotransmitter or neuromodulator to regulate physiological processes associated with feeding and energy homoeostasis (Amano \& Takahashi, 2009; Ludwig et al., 2001; Matsuda et al., 2007).

The fish $\mathrm{MCH}$ system differs from that in mammals with regard to the hormonal status of $\mathrm{MCH}$ and the presence of two genes, pmch and pmchl, with distinct genetic structures (Berman, Skariah, Maro, Mignot, \& Mourrain, 2009). The single PMCH gene of mammals and birds contains three exons and encodes a prohormone that generates an $\mathrm{MCH}$ that acts as a neurotransmitter (Breton, Presse, Hervieu, \& Nahon, 1993; Cui et al., 2017; Nahon, Presse, Bittencourt, Sawchenko, \& Vale, 1989). Zebrafish have this gene, named originally pmch2 (renamed here $p c m h$ ), but also possess a one-exon gene that ultimately produces a peptide with "melaninconcentrating activity" (Berman et al., 2009; Ono, Wada, Oikawa, Kawazoe, \& Kawauchi, 1988; Takayama, Wada, Kawauchi, \& Ono, 1989) (Figure 1). The mammalian $\mathrm{MCH}$, encoded by the three-exon gene, is almost identical to the 17-a.a. fish "MCH," encoded by the single-exon gene (Berman et al., 2009; Kawauchi, 2006; Kawauchi et al., 1983; Nahon et al., 1989; Ono et al., 1988). Because rat $\mathrm{MCH}$ was characterized after the fish peptide, both received the same name (Nahon et al., 1989). Synteny analysis indicates, however, that the mammalian and zebrafish three-exon genes are linked evolutionarily, and higher similarity exists between the $\mathrm{MCH}$ peptides encoded by the three-exon genes than that by the one-exon gene (named hereafter pmchl) (Figure 2a) (Berman et al., 2009). A few studies have compared the expression of the pmch genes in fish adapted to different backgrounds (Berman et al., 2009; Kang \& Kim, 2013; Mizusawa et al., 2015; Zhang et al., 2010), but it is unclear whether it is $\mathrm{MCH}$ or $\mathrm{MCHL}$ that mediates teleost background adaptation. Moreover, an evolutionary analysis of pmch and pmchl genes is lacking.

Our data indicate that pmchl-expressing cells extend "MCHL"positive axons to the zebrafish pituitary, while the pmch-expressing neurons extend " $\mathrm{MCH}$ "-positive axons dorsally in the brain, suggesting that $\mathrm{MCHL}$ rather than $\mathrm{MCH}$ has the hormonal role. We used the phylogeny of chordates to analyse the evolution of pomc, pmch and pmchl genes. We suggest an explanation for the differences in the mechanisms that evolved to regulate background adaptation by inferring ancestral relationships, and assessing associations with plastic colour change, the ability of $\alpha-\mathrm{MSH}, \mathrm{MCH}$ and $\mathrm{MCHL}$ peptides to be synthesized and secreted and to work as neuroendocrine hormones, as well as their effects on skin pigmentation. We propose that the evolution of background adaptation relates mainly to key changes in the pmch genes, with the topological structure of the pomc gene and the $\alpha-\mathrm{MSH}$ a.a sequence both conserved during evolution. We show that the intron-less pmchl gene appears only in the Teleostei lineage, possibly as a result of an ancestral retroposition or during the teleost-specific genome duplication (TSD). Based on our analyses, we suggest renaming the intron-less gene, originally named pmch in several fish (Kawauchi,
2006; Ono et al., 1988; Takayama et al., 1989), as pmchl, which is in concordance with the current zebrafish nomenclature convention and reflects its evolutionary origin. PMCHL gained "hormonal status" and is found only in teleosts, while the three-exon pmch peptide product was conserved as a brain neurotransmitter that regulates feeding behaviour. To be consistent with the evolutionary origin of both genes, in this paper we call the mammalian and fish three-exon gene, and the prehormone and the peptide generated, as pmch, $\mathrm{PMCH}$ and $\mathrm{MCH}$, respectively, and the fish intron-less gene, pmchl, and its corresponding peptides PCMHL and $\mathrm{MCHL}$. Of note, special care should be taken with the literature, as a different nomenclature was used.

\section{2 | MATERIALS AND METHODS}

\section{1 | Embryos and in vitro fertilization}

The Animal Care and Use Committee, U. Calgary, approved procedures involving zebrafish and Xenopus laevis embryos. X. laevis embryos were obtained from Chorionic Gonadotrophin (Intervet Canada Ltd., Kirkland, QC, Canada) induced egg production and in vitro fertilization according to standard procedures. Tupfel Longfin (TL) zebrafish (ZIRC, Eugene, OR) embryos were raised at $28.5^{\circ} \mathrm{C}$ in E3 medium supplemented with $0.25 \mathrm{mg} / \mathrm{L}$ methylene blue. Three-day-old larval zebrafish and $X$. laevis larvae were maintained for five additional days at $22^{\circ} \mathrm{C}$ on a white or black background. The chamber $(40 \mathrm{~cm}$ length $\times 20 \mathrm{~cm}$ width $\times 25 \mathrm{~cm}$ height) contained an overhead T5 bulb (F875 cool white light fluorescent; light output, 470 lumens; colour temperature, 4,000; colour rendering index, 60), with a luminescence at the embryo dish surface of 1,000 lux, approximately $1.4 \times 10^{-4} \mathrm{~W} / \mathrm{cm}^{2}$. Light was set to cycle with an automatic clock to $14 \mathrm{hr}$ ON/10 hr OFF.

\section{2 | Assessment of skin pigmentation}

Physiological skin pigmentation indices were measured on 8-dayold embryos at the middle of the light cycle period ( $7 \mathrm{hr} \mathrm{ON}$ ), as described previously (Bertolesi, Hehr, \& Mcfarlane, 2015). Briefly, pictures of the dorsal head of tadpoles were taken with identical conditions of light, time exposure and diaphragm aperture, and converted to binary white/black images using NIH Image J (U. S. National Institutes of Health, Bethesda, MD) public domain software. The areas of ten dorsal head melanophores/fish were measured $(n=10$ fish; $N=2$ experiments), while in Xenopus ( $n=10 ; N=2$ ) the pigmentation present within an area of the dorsal head between the eyes was used for quantification, since melanophore processes overlap. Statistical differences were determined by ANOVA $\left({ }^{*} p<0.05\right)$.

\subsection{Cloning and Fluorescent in situ hybridization (FISH)}

pmch and pmchl from zebrafish were amplified by reverse transcriptase PCR (RT-PCR) from single-strand cDNA generated from zebrafish embryos at 8 days post-fertilization (dpf) using SuperScript ${ }^{\mathrm{TM}}$ 
II RNase $\mathrm{H}$ reverse transcriptase (Invitrogen) according to the manufacturer's instructions. PCR amplifications were carried out in a total volume of $20 \mu$ using Fermentas PCR mix (Thermo Fisher Scientific Inc., Ottawa, Ontario). PCR amplification products were cloned into the pCRII-Topo vector and sequenced at the DNA Services Facility, U. Calgary. pCRII-TOPO-pmch-ZF and pCRII-TOPO-pmchl-ZF amplified by PCR produced sequences with $100 \%$ identity to those deposited previously in the GenBank database [FJ392644.1 between nucleotides 1 and 481 (pmch) and FJ204827.1 between nucleotides 15 and 452 (pmchl), respectively). A pCMV sport6 plasmid, containing the full-length cDNA encoding $X$. laevis pmch obtained from an image clone (Open Biosystems Image Clone number IC6947676; pCMV-Sport6-pmch-XI), was used to generate pmch probes. Antisense and sense riboprobes were synthesized from linearized plasmid using SP6 or T7 RNA polymerases (Roche) and digoxigenin (DIG) (Roche, Montreal, QC, Canada)-labelled nucleotides and stored at $-80^{\circ} \mathrm{C}$. FISH was performed on $12-\mu \mathrm{m}$ cryostat sections obtained from embryos at $8 \mathrm{dpf}$. Hybridized probes were detected using anti-DIG antibody (1:500; Roche) conjugated to horseradish peroxidase. The staining process was carried out with a TSA Cyanine 3 (red) system kit (Perkin Elmer, USA), according to the manufacturer's instructions.

\section{4 | Immunohistochemistry post-in situ hybridization}

Immunohistochemistry was performed on sections after FISH using standard procedures. Briefly, the FISH reaction was stopped with several washes of TN-T (100 mM Tris pH 7.5, $150 \mathrm{mM} \mathrm{NaCl}, 0.1 \%$ bovine serum albumin (Sigma), and 0.5\% Tween-20 (BDH)) before addition of primary antibody (anti-MCH rabbit polyclonal M8440; $1 / 100$ dilution; Sigma-Aldrich) in blocking buffer (0.5\% blocking

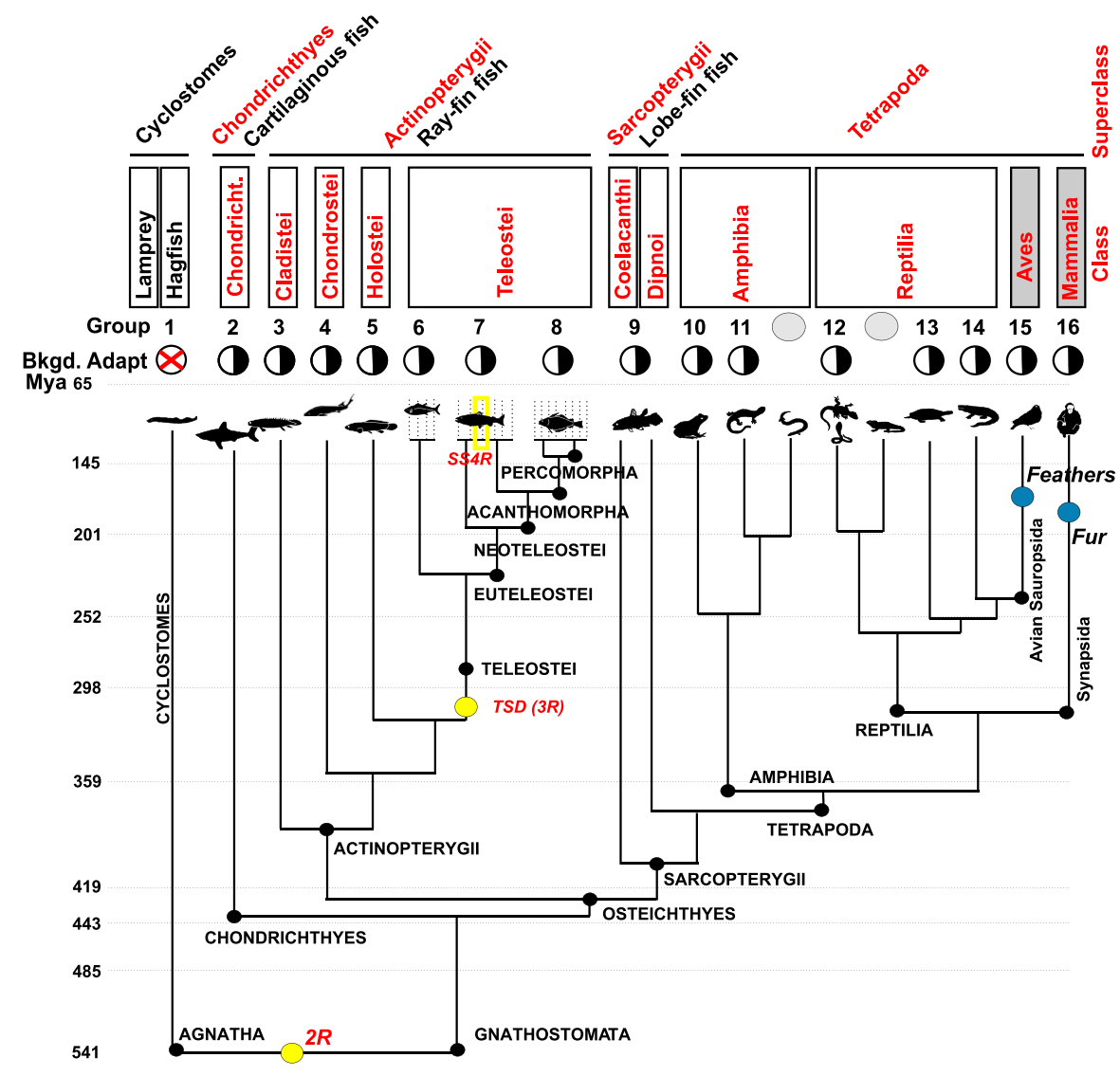

FIGURE 3 Schematic diagram of related taxa (classes or orders) of vertebrates with a similar state of evolution and/or mechanism for background adaptation. Extant species divided (see Materials and Methods) into 16 groups corresponding with taxonomic classes (top rectangles) or taxonomic orders. Evolutionary years (millions) dividing different era are indicated on the left. Whole-genome duplication events (2R; teleost-specific duplication [TSD 3R] and salmonid-specific duplication [SS 4R]) are indicated in yellow, while blue circles denote the age of the oldest preserved fossils with fur or feathers with insulation capacity. Homoeotherms (birds and mammals) are in grey boxes. Background adaptation is indicated with a white/black circle. Group 1: Cyclostome (agnathans: hagfish and lamprey); Group 2: Chondrichthyes (cartilaginous fish; sharks); Group 3: Cladistei (Polypteriformes; bichir); Group 4: Chondrostei (sturgeon); Group 5: Holostei (bowfin; gar); Group 6: Teleostei; Group 7: Euteleostei and Neoteleostei; Group 8: Acanthomorpha (See taxonomic orders for Groups 6, 7 and 8 in Table S2); Group 9: Coelacanthi and Dipnoi (lungfish); Group 10: Anura (frogs); Group 11: Caudata (salamanders); Group 12: Squamata (lizard and snakes); Group 13: Testudine (turtles); Group 14: Crocodilia (crocodiles, alligators); Group 15: Aves (birds); and Group 16: Mammalian (mammals). Not included in the analysis are the taxonomic orders from amphibian Gymnophiona (caecilians) and from reptile Rhynchocephalia (tuatara) (grey circle) 
reagent FP1020 in TN-T; Perkin Elmer). Alexa Fluor-tagged secondary antibodies (green; $488 \mathrm{~nm}$ emission, anti-rabbit) diluted 1:1,000 were used to detect the primary antibody.

\section{5 | Comparative genomic survey}

A variety of organisms from agnathans and gnathostomes with readily available protein reference sequence were used to probe for $\mathrm{PMCH}, \mathrm{PMCHL}$ and POMC. Homologues were identified using zebrafish PMCH, PMCHL and POMC as queries with a cut-off expect (E) value for positive candidates set at 0.05 . The organisms selected are listed in Tables S3 and S4 (pmch and pmchl) and 4 (pomc). The genetic-structural analysis of pmch and pmchl was performed from organisms listed in the NCBI gene database that contained the exonintron structure and gene identification number, as referred to in the organism list. Although organisms with fully sequenced genomes were chosen wherever possible, some organisms in key lineages with unpublished or incomplete genomes were also included. In a few cases, for example, for organisms that are used as model systems for background adaptation (i.e., Oncorhynchus keta and Verasper moseri), we included nucleotide sequence obtained from cDNA rather than derived from genomic sequences. Different species were chosen to represent a broad range of organisms in sixteen clades (taxonomic classes or orders) as referred to in Figure 3.

\subsection{Clades representing a similar state of evolution and/or background adaptation}

Vertebrates were divided into sixteen clades. Group 1 contains species in the infraphylum agnathan (cyclostomes, represented by two taxonomic classes, Myxini and Cephalaspidomorphi, which includes the hagfish and lamprey, respectively). Groups 2-16 correspond to extant gnathostomes. Group 2 contains the cartilaginous fish (sharks; taxonomic class, Chondrichthyes), while the ray-fin fish (Actinopterygii) were divided into six groups representing taxonomic classes or orders (Groups 3-8). The taxonomic classes Cladistei, Chondrostei and Holostei were maintained as independent groups (Groups 3, 4 and 5, respectively), while the clade Teleostei was divided into three groups based on the taxonomic orders and differences in their background adaptation response (see Results4 and Table S2). The 38 taxonomic orders in Teleostei were divided as follows: Group 6 (Teleostei) contains 11 taxa, Group 7 (Euteleostei plus Neoteleostei) contains 7 taxa, and Group 8 (Acanthomorpha plus Percomorpha) contains 20 taxa (Table S2). Lobe-fin fish (Sarcopterygii) were Group 9. The amphibians were grouped into their three taxonomic orders: Anura (frogs; Group 10), Caudata (salamanders; Group 11) and Gymnophiona (caecilians, not analysed because of lack of information on pomc, pmch and pmchl). Reptiles were also grouped according to their taxonomic order: Squamata (lizards and snakes; Group 12); Testudine (turtles; Group 13); Crocodilia (crocodiles; Group 14); and Rhynchocephalia (tuataras), with the latter not considered because only one living species (Sphenodon punctatus) exists and genetic information is lacking.
Finally, Groups 15 and 16 correspond to the clade Aves (birds) and Mammals, respectively.

\section{7 | Alignment and phylogenetic analysis}

Validated sequences were aligned using MUSCLE (multiple sequence alignment) and used to build a hidden Markov model (HMM) by using a maximum-likelihood architecture construction algorithm. All phylogenetic analysis and alignments were performed by using the public domain MEGA X software (www.megasoftware.net) (Kumar, Stecher, Li, Knyaz, \& Tamura, 2018). Detailed descriptions and statistics are indicated in the figure legends.

\section{3 | RESULTS AND DISCUSSION}

\section{1 $\mathrm{MCHL}$, but not $\mathrm{MCH}$, neurons extend axons to the pituitary, suggesting that $\mathrm{MCHL}$ possesses "hormonal status"}

$\mathrm{MCH}$ and $\mathrm{MCHL}$ show a similar a.a. sequence (Figure $2 \mathrm{a}$ ), and both bind cultured mammalian HEK293 cells that overexpress MCH1R and MCH2R (Mizusawa et al., 2015). The data are more convincing, however, for MCHL having "hormonal status." At physiological concentrations ( $<1 \mathrm{nM}$ ), MCHL induces greater melanosome aggregation in cultured skin melanophores and xanthophores than $\mathrm{MCH}$ (Mizusawa et al., 2015). Further, MCHL is the "factor" with melanin-concentrating capacity that was shown initially to be secreted by the pituitary of catfish (Parasilurus asotus) (Enami, 1955), and was then purified from the pituitary of Chum salmon (O. keta) (Figure 2a) (Enami, 1955; Kawauchi et al., 1983). Finally, pmchl mRNA is upregulated in organisms with a white background (Berman et al., 2009; Kang \& Kim, 2013; Mizusawa et al., 2015; Zhang et al., 2010), and pmchl overexpression in medaka (Oryzias latipes) increases MCHL plasma levels and lightens the skin, but leaves feeding behaviours unchanged (Kinoshita et al., 2001). These data argue that MCHL has hormonal status.

Whether the related $\mathrm{MCH}$ is also secreted into the circulation blood to induce melanosome aggregation is unclear. In order to answer this question, we used two experimental models: zebrafish (Danio rerio) and the African clawed frog (X. laevis), which possess $\mathrm{MCH} / \mathrm{MCHL}$ and only $\mathrm{MCH}$, respectively (Figure 2a). Of note, studies have defined the hormonal status of an $\mathrm{MCH}$ in fish based on the immunohistochemical detection of $\mathrm{MCH}+$ axon fibres that project to the neurohypophysis (Baker, 1993; Baker \& Bird, 2002; Powell \& Baker, 1988) and/or the biochemical detection of $\mathrm{MCH}$ peptides in blood (Baker et al., 1984; Kishida et al., 1989). Those studies, however, were performed before it was known that two pmch genes exist, and used polyclonal antibodies raised against either mammalian $\mathrm{MCH}$ (human or rat) or salmonid MCHL (Coho salmon), which likely cross-react in that $\mathrm{MCH}$ and $\mathrm{MCHL}$ a.a. sequences are almost identical (Figure 2a). In order to compare the background adaptation response between the two model systems, we grew three-dayold zebrafish and Xenopus larvae for 5 days with a white or a black 
background, and then measured skin pigmentation (Bertolesi et al., 2015). Both species showed melanosome aggregation and a light skin colour with a white background (Figure 2b). Next, we asked whether the pmch+ and pmchl+ neurons in zebrafish and the pmch+ neurons of Xenopus are present in the hypothalamus, and project axons to the neurohypophysis. Of note, in zebrafish pmch and pmchl are expressed by different neurons (Berman et al., 2009), arguing for distinct roles of the two peptides. We used a polyclonal antibody raised against human $\mathrm{MCH}$, alongside in situ hybridization for pmch and pmchl. The antibody labelled both pmch+ and pmchl+ cells in zebrafish, indicating it recognized both peptides.

A clear difference was observed when we tracked the $\mathrm{MCH}$ / MCHL-positive axon projections from the pmch+ or pmchl+ cells. The pmchl+ cells localized close to the pituitary and projected their axons to the neurohypophysis, while in both Xenopus and zebrafish, $\mathrm{MCH}$ expressing axons of pmch+ cells projected mainly dorsalwards within the brain (Figure 2c), suggesting a hormonal status for MCHL but not $\mathrm{MCH}$ in zebrafish. Together, these results suggest that in fish $\mathrm{MCHL}$ possesses hormonal status to regulate background adaptation, while $\mathrm{MCH}$ in fish and frogs likely acts as it does in mammals, as a neurotransmitter that participates in physiological responses associated with homoeostasis and feeding behaviours (Figure 2c).

\section{2 | Vertebrates organized in sixteen clades representing a similar state of evolution and/or a mechanism for background adaptation}

Our experimental data suggest MCHL possesses hormonal status in zebrafish, while $\mathrm{MCH}$ may act as a brain neurotransmitter. Together with the presence of two pmch genes in fish and one in mammals, these observations led us to hypothesize that the uni-hormonal or dual-hormonal theories of background adaptation in vertebrates might be explained by the evolution of the pomc, pmch and pmchl genes. To address this possibility, we assessed in species across evolution first the presence of a physiological background adaptation response, via an analysis of the literature, and, second, the structure and sequences of the pomc, pmch and pmchl genes and their corresponding peptides. Thus, the evolution of the physiological background adaptation response was inferred by comparison of extant organisms grouped in 16 clades (taxonomic classes or orders) as referred to by the Integrated Taxonomic Information System (https://www.itis.gov/) (Figure 3).

We focused our evolutionary analysis on two assemblages in the phylum Chordata that emerged over the past 500 million years: the agnathans (bilateral organisms with an internal support system but that lack a hinged jaw; Cyclostome; Group 1) and the gnathostomes (bilateral organisms with an internal cartilaginous or bony skeleton, and a hinged jaw; Groups 2-16). The Protochordata (organisms that lack an internal cartilaginous or bony skeleton) were not considered in this study, since the mechanisms to change skin colour differ from those in Chordata (Umbers, Fabricant, Gawryszewski, Seago, \& Herberstein, 2014), and the pomc gene is not detected (Sundström, Dreborg, \& Larhammar, 2010).

Cyclostomes (Group 1) change skin colour in response to environmental light (dark/light) through melatonin secreted by the pineal gland (Joss, 1973); however, we are unaware of reports of quick physiological skin adaptation prompted by changing the surface colour (Figure 3, circle with a red cross). Background adaptation does occur in extant gnathostomes starting in Group 2 (cartilaginous fish; Chondrichthyes) with sharks altering their skin pigmentation to adapt to the "background" colour generated by deep and shallow water (Lowe \& Goodman-Lowe, 1996), and continuing through to mammals (Beltran, Burns, \& Breed, 2018; Zimova et al., 2018) (Figure 3, black and white circles; see additional references in Table S1).

The ray-finned bony fish (Groups 3-8; Actinopterygii) constitute the largest clade of living vertebrates and distribute over Cladistei, Chondrostei, Holostei and Teleostei taxa (Figure 3). Here, we maintained three of the four taxonomic classes (Cladistei, Chondrostei and Holostei, with 11, 31 and 8 living species, respectively) as independent groups (Groups 3, 4 and 5, respectively), with all containing species that background-adapt (Figure 3 and Table S1). The fourth Actinopterygii taxonomic class, Teleostei, contains more than 27,000 species. We divided this clade into three groups that reflect different evolutionary lineages based on recent molecular and genomic data (Groups 6-8) (Betancur-R et al., 2013; Betancur-R et al., 2017; Near et al., 2012).

Group 6 contains the earliest teleost lineages and includes Cypriniforme zebrafish (D. rerio) and the Anguilliforme eel (Anguilla Anguilla) with a dual-hormonal mechanism (Figure 3, Tables S1 and S2). Group 7 contains the Euteleostei plus Neoteleostei (Figure 3 and Table S2). Background adaptation occurs in the Esociform Esox lucius, as well as in several species of salmonids, including Oncorhynchus mykiss, and the Chum salmon (O. keta) from which an $\mathrm{MCH}$ peptide (we call $\mathrm{MCHL}$ ) was originally purified (Kawauchi et al., 1983). Studies in salmon helped reveal the dual-hormonal mechanism, in that circulating $\mathrm{MCH} / \mathrm{MCHL}$ and $\alpha$ MSH levels increase with a white and black background, respectively (Baker et al., 1984; Kishida et al., 1989) (Figure 3 and Table S1). Finally, Group 8, Acanthomorpha, are collectively known as the spiny-rayed fish (Figure 3). Percomorphas, the clade that encompasses most of the diversity of modern Acanthomorpha, is the major evolutionary lineage at the top of the teleost tree (Figure 3 and Table S2). Organisms of this group backgroundadapt and include the important models Beloniforme medaka (Oryzias latipes), Tetraodontiforme fugu (Takifugu rubripes) and the Pleuronectiforme flounder (Verasper moseri) (Klovins et al., 2004; Mizusawa, Kobayashi, Yamanome, Saito, \& Takahashi, 2013; Sugimoto et al., 1997). Interestingly, several species in this group lack the dual-hormonal mechanism, in that $\mathrm{MCH} / \mathrm{MCHL}$ plasma levels but not $\alpha$-MSH vary with background adaptation, including flounders (Verasper moseri and Platichthys flesus) (Gilham \& Baker, 1984; Kang \& Kim, 2013; Mizusawa et al., 2011) and tilapias from the genus Oreochromis (Nile and Mozambique) (Gröneveld, Balm, Martens et al., 1995a; Gröneveld, Balm, \& Wendelaar Bonga, 1995b; van der Salm, Metz, Wendelaar Bonga, \& Flik, 2005).

Group 9 consists of the Coelacanthi and Dipnoi lobe-finned fish (lung fish), with only eight living species (Figure 3). Captive Dipnoi 
adapt their skin colour to the background (Smith \& Coates, 1936), while no information is available for coelacanths.

To best characterize evolutionary changes in pomc and pmch, we grouped the species in the taxonomic classes Amphibia and Reptilia according to their taxonomic orders (Figure 3): the amphibian frogs (Anura; Group 10), salamanders (Caudata; Group 11) and caecilians (Gymnophiona; not analysed, grey circle), and the Reptilia Squamata (lizards and snakes; Group 12), Testudine (turtles; Group 13), Crocodilia (crocodiles; Group 14) and Rhynchocephalia (tuataras not analysed, grey circle) (Figure 3). Although colour skin pigmentation of several species of caecilians mimics the above-ground soil where they move (Wollenberg \& Measey, 2009), is not clear if it is a genetically mediated process (background matching) or driven by physiological colour plasticity. Therefore, caecilians were not grouped for further analysis. In contrast, background adaptation in amphibian frogs and salamanders is well documented (Table S1) and appears to be driven by a uni-humoral mechanism, since $\mathrm{MCH} / \mathrm{MCHL}$ do not trigger melanosome aggregation (Ferroni \& Castrucci, 1987; Wilkes et al., 1984). Background adaptation is also present in species in the clade Reptilia (Figure 3 and Table S1).

Finally, the homoeotherms of the taxonomic classes Aves (birds; Group 15) and Mammals (Group 16) correspond to the last two groups analysed (Figure 3; homoeotherms grey boxes). Melanocytes are the only pigment cells found in the integument of birds and mammals. With the development of feathers and fur in birds and mammals, respectively (thermal insulation systems), melanocytes became secretory, contributing melanin to surrounding keratinocytes to determine feather/hair pigmentation (Lin et al., 2013; Parichy \& Spiewak, 2015). Common climate factors may have contributed to evolution of endothermy in both lineages, since the oldest preserved fossils with fur (Ji, Luo, Yuan, \& Tabrum, 2006) and feathers (Prum \& Brush, 2002) with insulation capacity come from a similar evolutionary time, but arose independently in the Avian-Sauropsida (birds) and Synapsida (mammals) lineages (Lovegrove, 2017) (Figure 3; blue circle; feathers and fur). Background adaptation in both lineages involves neuroendocrine regulation of coloration through melanocyte deposition of eumelanin (grey/black) or pheomelanin (orange/red) into feathers and fur, though colour in birds comes also from the dietary contribution of pigment carotenoids (Roulin \& Ducrest, 2013).

In summary, our analysis indicates that living gnathostomes, from Chondrichthyans (Group 2) to all Osteichthyans (Groups 3-16), are able to adapt their skin colour to different backgrounds (Figure 3 black/ white circle), while agnathans (living cyclostomes) do not. Thus, background adaptation in vertebrates seems to have appeared early during the radiation of gnathostomes. Interestingly, the role of $\alpha-\mathrm{MSH}$ and $\mathrm{MCH} / \mathrm{MCHL}$ peptides changed during evolution, with species adapting to background through either a uni- or dual-humoral mechanism.

\section{3 $\mathrm{MCH}$ is conserved during evolution, while MCHL appears only in Teleostei}

We next performed an evolutionary analysis of the $\mathrm{MCH}$ and $\mathrm{MCHL}$ peptides and genes. We focused first on the gene structure of pmch, analysing mainly organisms whose genome was fully sequenced and listed in the NCBI gene database with the exon-intron structure and gene identification number (Table S3). The three-exon gene appears conserved during evolution, as it is present in all groups in which we were able to find the gene, from Chondrichthyes (Group 2) to Mammals (Group 16). In contrast, the intron-less gene is present only in teleost fish (Groups 6-8; Figure 4 and Table S3). Teleosts possess $\sim 30 \%$ more pigmentation-related genes than tetrapods, most of which were duplicated and retained during the TSD and are involved in specification and differentiation of pigment cells (Braasch, Brunet, Volff, \& Schartl, 2010; Lorin, Brunet, Laudet, \& Volff, 2018). Thus, the idea that $p m c h l$ was retained in Teleostei by evolutionary pressure selection on a gene with a key role in pigmentation regulation (e.g., background adaptation) is tempting.

Based on these analyses, and lack of demonstrated function in pigmentation, we argue for the renaming of the original pmch2 gene (Berman et al., 2009) as pmch, in recognition of its conservation across species. Because the intron-less gene is present in fish, but is not conserved during evolution, we suggest naming this gene pmchl in accordance with Zebrafish Nomenclature Convention. Two pmch and two pmchl genes exist in species of the taxonomic order Salmoniform, but only one in non-salmonid species of Group 7 (i.e., Esociform Esox lucius) or Group 6 (D. rerio) (Figures 4 and 5 and Table S3). Variants of $p c m h$ and $p c m h l$ originated presumably as a result of the salmonid-specific fourth vertebrate whole-genome duplication (SS4R), which occurred 80 mya in the common ancestor of the salmonid lineage (Lien et al., 2016) (Figure 3, yellow rectangle in Group 7). We suggest the genes should be named pmcha and pmchb, and pmchla and pmchlb, respectively. pmchla and pmchlb are present in O. keta (named $\mathrm{MCH} 1$ and $\mathrm{MCH} 2$ ) (Ono et al., 1988), O. mykiss (MCH1 and MCH2) (Baker, Levy, Hall, \& Lightman, 1995), O. tshawytscha (MCH1 and $\mathrm{MCH} 2)$ (Minth, Qiu, Akil, Watson, \& Dixon, 1989) and O. kisutch (MCH1) (Nahon, Presset, Schoepfer, \& Vale, 1991). We find four variants in the Arctic char (Salvelinus alpinus) and the Atlantic salmon (Salmo salar), which express the mRNAs (Leong et al., 2010) (Figure 5 and Table S3). Phylogenetic analysis of the predicted proteins of the Group 7 salmonids and the Esociform Esox lucius shows that PMCHA and $\mathrm{B}$, and PMCHLA and PMCHLB are related to $\mathrm{PMCH}$ and PMCHL from Esox lucius, respectively, but appeared more recently in evolution (Figure 5). This result, together with the absence of the intron-less gene in Holostei and Tetrapoda, suggest that pmchl was generated early in the Teleostei lineage, possibly by retroposition or during the TSD with loss of the intron/exon organization. The TSD occurred $\sim 320$ mya, following the split of Teleostei from the other three taxonomic classes (Cladistei, Chondrostei and Holostei), but prior to the divergence of the other major Teleostei groups (Figure 3; TSD) (Hoegg, Brinkmann, Taylor, \& Meyer, 2004).Thus, the three-exon pmch gene was probably the original gene and conserved throughout evolution, while pmchl appeared in the teleost lineage. Both pmch and pmchl duplicated more recently in salmonids (SS4R). Of note, mammalian genomes contain a single $\mathrm{MCH}$ gene with three exons (NM_002674.3; gene 


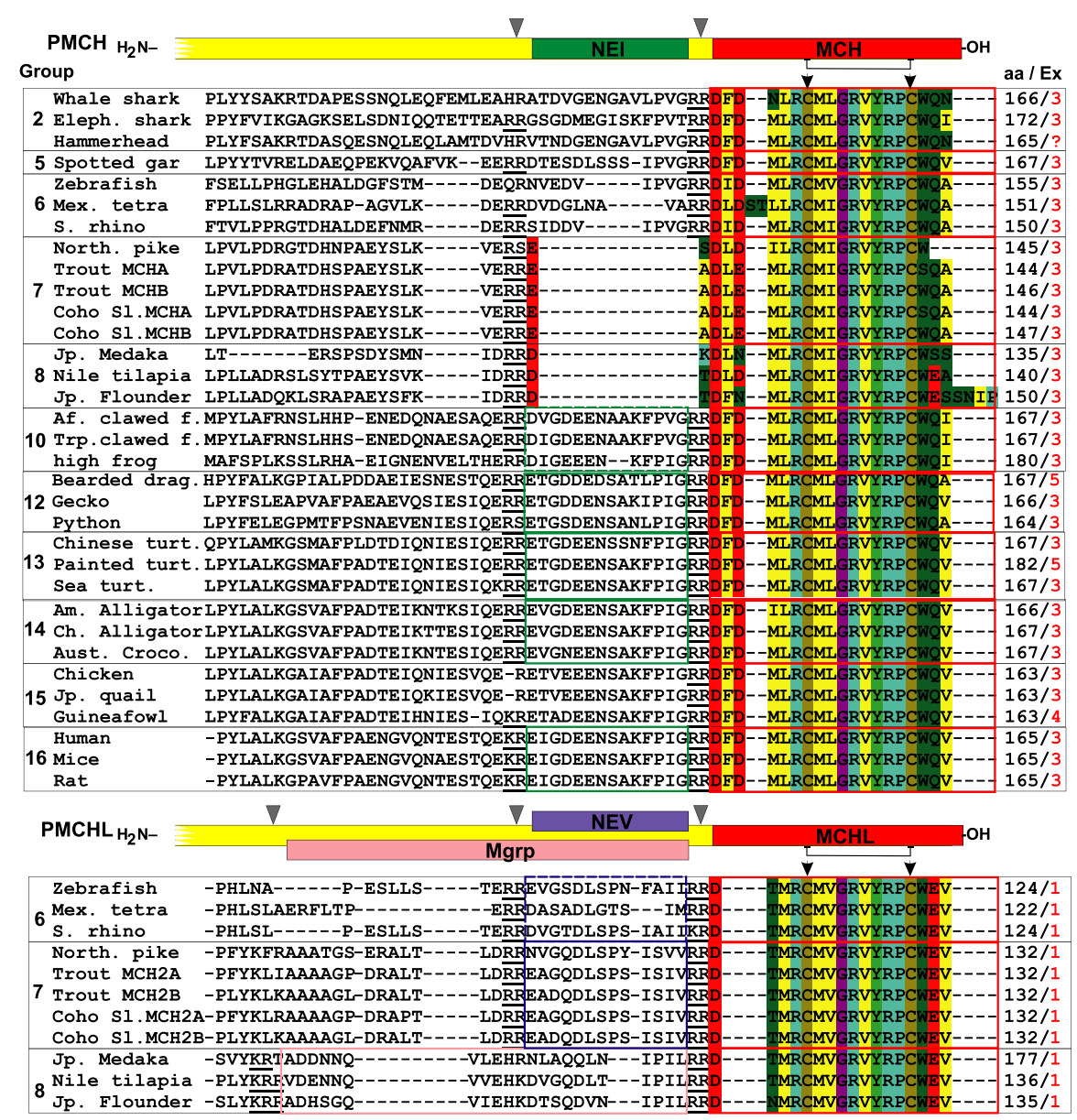

FIGURE 4 Carboxy-end amino acid sequence of the evolutionary conserved PMCH and the teleost-specific PMCHL. Structure (top) and alignment of the carboxy-end region of $\mathrm{PMCH}$ and $\mathrm{PMCHL}$ of several species grouped as indicated in Figure 3 . The putative peptides processed from $\mathrm{PMCH}$ include $\mathrm{MCH}$ and neuropeptide glutamic acid-isoleucine (NEI), and from PMCHL include $\mathrm{MCHL}$, neuropeptide glutamic acid-valine (NEV) and MCH gene-related peptide (Mgrp). The length of the a.a. sequences and the number of exons (Ex; red) that contribute to the open reading frame are indicated on the right. Note three (or more) exons and one exon contribute to PMCH and $\mathrm{PMCHL}$, respectively. Multiple protein sequence alignments were performed by using MUSCLE and correspond to PMCH from Group 2 [(Species; GenBank Acc. No.) (Whale shark; XP_020369308.1); (Elephant Shark; XP_007893646.1); (Hammerhead; BAM63324.1)], Group 5 (Spotted gar; XP_015207385.1), Group 6 [(Zebrafish; NP_001189471.1); (Mexican tetra; XP_022527487.1); (S. rhinocerous; XP_016390476.1)], Group 7 [(Northern pike; XP_010902154.1); (rainbow trout; pmcha: XP_021432849.1; pmchb: XP_021419487.1); (Coho salmon; pmcha: XP_020346541.1; pmchb: XP_020346566.1)], Group 8 [(Japanese medaka; XP_004083313.1); (Nile tilapia; XP_005475951.1); (Japanese flounder; XP_019960507.1)]; Group 10 [Xenopus laevis; XP_018110183.1); (Xenopus tropicalis; XP_002936876.1); (High frog; XP_018415182.1)], Group 12 [(Central bearded dragon; XP_020660073); (Gecko; XP_015278938.1); (Burmese python; XP_007420018.1)], Group 13 [(Chinese turtle; XP_006138097.1); (Painted turtle; XP_023964185.1); (Green sea turtle; XP_007072332.1)], Group 14 [(American alligator; XP_006277330.1); (Chinese alligator; XP_006019570); (Australian saltwater crocodile; XP_019400295)], Group 15 [(chicken; NP_001182724.1); (Japanese quail; XP_015720129.1); (Helmeted guinea fowl; XP_021243195.1)], Group 16 [(human; NP_002665.2); (mouse; NP_084247.1); (rat; NP_036757.1)] and PMCHL from Group 6 [(zebrafish; NP_001155960.1); (Mexican tetra; XP_007236729.2); (S. rhinocerous; XP_016406332.1)], Group 7 [(Northern pike; XP_010876172.1); (rainbow trout; pmchla: XP_021458034.1; pmchlb: XP_021446538.1); (Coho salmon; pmchla: XP_020312904.1; pmchlb: XP_020321819.1)] and Group 8 [(Japanese medaka; XP_004075131.2); (Nile tilapia; XP_003440133.1); (Japanese flounder; XP_019960696.1)]

number 5367), and two MCH-like genes, PMCHL1 (NR_003921.1; gene number 5369) and PMCHL2 (NR_003922.1; gene number 5370), but the latter two genes arose during primate evolution and are chimeric (non-coding) four-exon pseudogenes of unknown function (Courseaux \& Nahon, 2001).

We next analysed $\mathrm{PMCH}$ and $\mathrm{PMCHL}$ at the a.a. level. Both $\mathrm{PMCH}$ and $\mathrm{PMCHL}$ contain a predicted $\mathrm{MCH}$ and $\mathrm{MCHL}$ sequence able to generate a cyclic ring with 8 a.a. between two internal cysteines that mediate a disulphide bond essential for receptor binding (Audinot et al., 2001; Matsunaga, Hruby, Lebl, Castrucci, \& Hadley, 1992), as well as two consecutive basic residues (e.g., $\mathrm{Arg}^{145}$ - $\mathrm{Arg}^{146}$ in mammals and rodents) critical for cleavage and release (Viale et al., 1999) (Figures 2a and 4). MCH peptides are at least two a.a. longer (19-25 a.a. 64/65 species) than MCHL (17 a.a. 41/41 species in Groups 6-8). The latter is highly conserved (>94\% identity, 16/17 a.a.) in all species of Groups 6-8 (Figure 4 and Table S3). Also, highly conserved in 


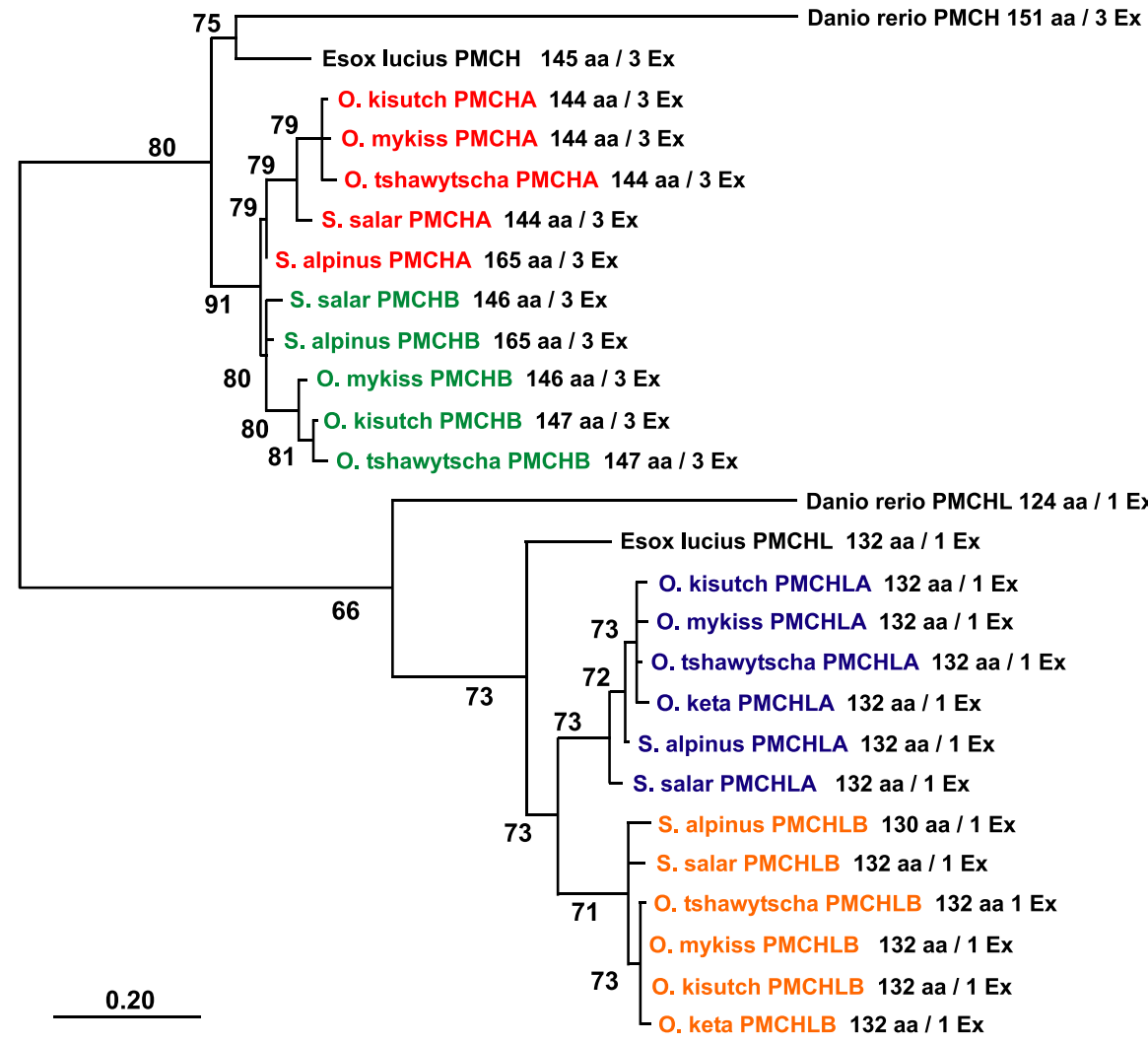

FIGURE 5 Molecular phylogenetic analysis by the maximum-likelihood method of salmonid PMCH and PMCHL. The evolutionary history was inferred using the maximum-likelihood method based on the JTT matrix model. The tree with the highest log-likelihood $(-2,119.89)$ is shown. Initial tree(s) for the heuristic search was obtained automatically by applying Neighbor-Join and BioNJ algorithms to a matrix of pairwise distances estimated using a JTT model, and then selecting the topology with superior log-likelihood value. The tree is drawn to scale, with branch lengths measured in the number of substitutions per site. The analysis involved 26 a.a. sequences corresponding to an outgroup Danio rerio (Group 6) (GenBank Acc. Nos.: PMCH: NP_001189471.1; and PMCHL: NP_001155960.1); a nonSalmoniform from Group 7, Esox lucius (PMCH: XP_010902154.1 and PMCH2: XP_010876172.1); and the salmonids Oncorhynchus mykiss (PMCHA: XP_021432849.1; PMCHB: XP_021419487.1; PMCHLA: XP_021458034.1 and PMCHLB: XP_021446538.1), O. kisutch (PMCHA: XP_020346541.1; PMCHB: XP_020346566.1; PMCHLA: XP_020312904.1 and PMCHLB: XP_020321819.1), O. tshawytscha (PMCHA: XP_024228562.1; PMCHB: XP_024232986.1; PMCHLA: XP_024237102.1 and PMCHLB: XP_024252615.1), O. keta (PMCHLA: AAA49418.1 and PMCHLB: AAA49419.1), Salmo salar (PMCHA: XP_014063826.1; PMCHB: XP_014008839.1; PMCHLA: NP_001135051.1 and PMCHLB: XP_013984342.1) and Salvelinus alpinus (PMCHA: XP_023831908.1; PMCHB: XP_023825197.1; PMCHLA: XP_023838986.1 and PMCHLB: $X P_{-}$023842930.1). There were a total of 182 positions in the final data set. Evolutionary analyses were conducted in MEGA X (Kumar et al., 2018). The number of amino acids (aa) and exons (Ex) encoding the prehormones, as well as bootstrapping values (\%), are indicated

MCHL is a valine ${ }^{7}$ inside the ring (41/41 species from Groups 6-8). In $\mathrm{MCH}$, the a.a. at this site is isoleucine or leucine, except for in two Group 6 species, D. rerio and Paramormyrops kingsleyae, in which valine is present (Figure 4).

We next analysed the presence of other putative peptides in the $\mathrm{PMCH}$ and $\mathrm{PMCHL}$ prohormones. In mammals, $\mathrm{PMCH}$ is processed to $\mathrm{MCH}$ and neuropeptide glutamic acid-isoleucine (NEI) (Viale et al., 1999), a 13-a.a. peptide that affects the hypothalamic-gonadal axis (Bittencourt \& Celis, 2008; Fujimoto, Fukuda, Sakamoto, Takata, \& Sawamura, 2017). Conserved sequence for the mammalian NEI is present in amphibians and reptiles (Groups 10-14), while several a.a. are absent from Group 6 species and missing completely from Group 7 and 8 species (Figure 4). These data suggest that NEI has no biological function in teleosts. Similarly, in birds (Group 15), the predicted NEI peptide is highly modified, and the loss of the K/R R site for cleavage in chicken and Japanese quail (Figure 4) suggests that the peptide is not processed and released. Thus, NEI is conserved in land organisms, but not aquatic organisms or birds. Interestingly, a arginine-valine (NEV) neuropeptide from the rainbow trout sequence was suggested as a homologue of the mammalian NEI, based mainly on the topological position and the presence of a dibasic RR motif (Baker et al., 1995; Nahon et al., 1989). Our analysis shows that $\mathrm{NEV}$ is predicted to be processed from $\mathrm{PMCHL}$ but not $\mathrm{PMCH}$, and in species from Groups 6 and 7, but not Group 8 (Figure 4). An additional putative peptide, named $\mathrm{MCH}$ gene-related peptide (Mgrp) (Figure 4), is present in Nile tilapia, but does not participate in background adaptation (Gröneveld, Balm, \& Wendelaar Bonga, 1995c). The alignment of the various $\mathrm{PMCHL}$ shows an Mgrp putative sequence only in Group 8 species, where Nile tilapia sits (Figure 4), supporting the idea that taxonomic grouping of fish reflects evolutionary lineage. Of note, mass spectrometry shows Mgrp is present in the pituitary of Group 8 medaka (Oryzias latipes) (Suehiro et al., 
2009), but not in flounders (Verasper moseri and Astatotilapia burtoni), although $\mathrm{PMCH}, \mathrm{PMCHL}, \mathrm{MCH} / \mathrm{L}$ peptides are all present $(\mathrm{Hu}$ et al., 2016; Takahashi et al., 2004).

Thus, the three-exon gene is translated to $\mathrm{PMCH}$, which then releases $\mathrm{MCH}$ after processing. In mammals, and probably in fish (Berman et al., 2009; Mizusawa et al., 2012), MCH acts as a neurotransmitter to regulate feeding. The paralogue $\mathrm{pmchl}$ intron-less gene (originally named $p m c h$ ), and the $\mathrm{MCHL}$ peptide to which it gives rise, appears only in Teleostei. Its existence, coupled with the potential of MCHL to reach the circulation, associates with the dualhormonal mechanism for background adaptation in teleosts.

\subsection{The highly conserved $\alpha-\mathrm{MSH}$ of gnathostomes associates with background adaptation}

With $\alpha-\mathrm{MSH}$ as a key regulator of background adaptation, and data which suggest that pomc and mcr1 in chordates are linked evolutionarily (Dores \& Baron, 2011; Dores et al., 2016), we next analysed the a.a. sequences of POMC, $\alpha-\mathrm{MSH}$ and ACTH. ACTH and $\alpha-\mathrm{MSH}$ arise from processing of $\mathrm{POMC}$ in the anterior pituitary and pars intermedia pituitary, respectively, and are utilized in distinct neuroendocrine circuits (Zhou, Bloomquist, \& Mains, 1993) (Figure 6a). $\beta$-, $\gamma$ - and $\delta$-MSH are also processed from POMC, but have no known role in

(a)

SMSH $\beta M S H$ End.

$\alpha \mathbf{M S H}$

Sea lamprey (POC)
1 Sea lamprey (POM)
2 Dogfish
3 Senegal Bichir
4 Chinese sturgeon
5 Spotted gar
6 Zebrafish
7 Northern Pike
8 Jp. Medaka
9 West Af. Lungfish
10 Af. Clawed frog
11 Mudpuppy
12 Green anole
13 Chinese turtle
14 Am. Alligator
15 Chicken
16 Human

(b)

\begin{tabular}{|c|c|c|c|}
\hline & 157 & & \multirow{3}{*}{$\begin{array}{r}245 \\
\text { HFRW }\end{array}$} \\
\hline & 112 & HFRW & \\
\hline HFRW & 146 & HFRW & \\
\hline HFRW & 146 & HFRW & 259 \\
\hline HFHW & 145 & HFRW & 264 \\
\hline HFRS & 140 & HFRW & 259 \\
\hline & 113 & HFRW & \multirow[t]{2}{*}{220} \\
\hline & 105 & \begin{tabular}{l|l} 
HFRW \\
\end{tabular} & \\
\hline & 88 & HFRW & 212 \\
\hline HFRW & 138 & HFRW & 255 \\
\hline HFRW & 145 & HFRW & 259 \\
\hline HFRW & 148 & HFRW & 262 \\
\hline HFRW & 136 & HFRW & \multirow{2}{*}{$\begin{array}{l}240 \\
261\end{array}$} \\
\hline HFRW & 144 & HFRW & \\
\hline HFRW & 142 & HFRW & 261 \\
\hline HFRW & 137 & HFRW & \multirow{2}{*}{$\begin{array}{l}251 \\
267\end{array}$} \\
\hline HFRW & 143 & HFRW & \\
\hline & $\alpha \mathbf{M S H} I$ & & \\
\hline
\end{tabular}

Sea lamprey (POC) AKR SVSSPKYAMGHFRWGSPDKATIRKR--RPVRP-NTSDSPEI PDYAFNGVE 1 Sea lamprey (POM) KRVQESADGYRMOHFRWGQ LEGKKRQPEQSQGVPLGMGSDENARVVNGGQAW

2 Dogfish

3 Senegal Bichir

4 Chinese sturgeon

5 Spotted gar

6 Zebrafish

7 Northern Pike

$8 \mathrm{Jp}$. Medaka

9 West Af. Lungfish

10 Af. Clawed frog

11 Mudpuppy

12 Green anole

13 Chinese turtle

14 Am. Alligator

15 Chicken

16 Human

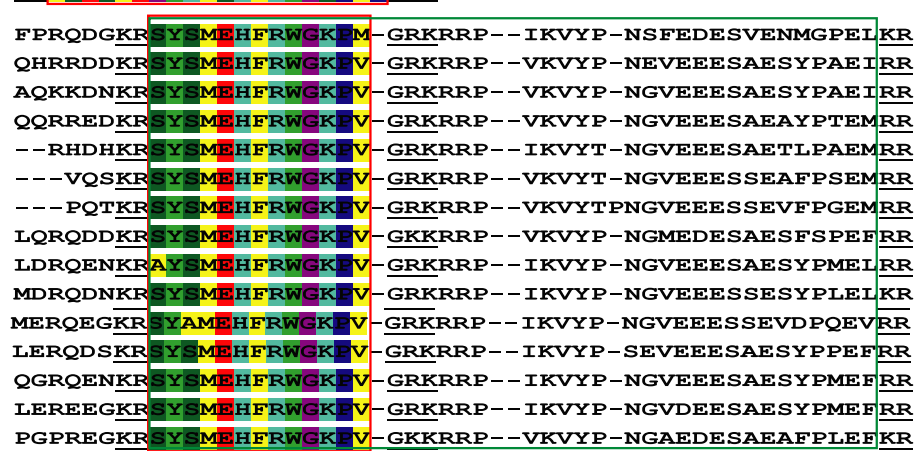

FIG URE 6 Topological organization of POMC and amino acid sequence alignment of ACTH/ $\alpha-M S H$. (a) Schematic representation of POMC with the positioning of the different processed peptides. $\gamma-\mathrm{MSH}, \beta-\mathrm{MSH}, \mathrm{ACTH}$ (green) and $\alpha-\mathrm{MSH}$ (red), which is at the amino-end of ACTH, are indicated and positioned based on the presence of the conserved HFRW sequence. $\beta$-Endorphin is located at the carboxy-end. The a.a. length and the position of the first a.a. of HFRW are indicated on the right and inside the ACTH/ $\alpha-\mathrm{MSH}$ domain, respectively. Note that $\delta$-MSH is exclusive to Group 2 (sharks) and $\gamma-\mathrm{MSH}$ is not present in teleosts (Groups 6, 7 and 8), cyclostomes (Group 1) and the lineage from which arose the snakes (Group 12), but is present in lizards (half blue rectangle). Also indicated are mutations in HFRW in Groups 4 and 5 species. In lamprey, ACTH and $\alpha-\mathrm{MSH}$ are encoded by different genes, named pom and poc, respectively (Heinig et al., 1995; Takahashi et al., 1995). (b) Aligned sequences of $\mathrm{ACTH}$ and $\alpha-\mathrm{MSH}$ (green and red box, respectively). Amino acids in $\alpha-\mathrm{MSH}$ are coloured. Note similarity between Groups 2 to 16. Topological organization and sequence alignment were performed by using the following POMC prohormones (species, GenBank Acc. No.): Sea lamprey (POC), BAE16561.1; Sea lamprey (POM), BAE16562.1; dogfish, BAA32606.1; Senegal bichir, AAL73510.1; Chinese sturgeon, CD12131.1; Spotted gar, XP_015206930.1; Zebrafish, NP_852103.1; Northern pike, XP_010904355.1; Japanese medaka, XP_004066504; West African lungfish, AAD29144.1; African clawed frog, NP_001080838; Mudpuppy, AAN46359.1; Anolis carolinensis, XP_003227954.1; Chinese turtle, NP_001273847.1; American alligator, NP_001274535.1; Chicken, NP_001026269.1; and Human, NP_000930.1 
background adaptation (Gilham \& Baker, 1984; Sumpter \& Lowry, 1984). For Group 1 cyclostomes, we analysed the peptides that would arise from two genes with homology to pomc, pom (pro-opiomelanotropin) and poc (pro-opiocortin), which contain the ACTH and the $\alpha-\mathrm{MSH}$ sequences, respectively (Heinig, Keeley, Robson, Sower, \& Youson, 1995; Takahashi et al., 1995). Common to ACTH and all three MSH peptides is the presence of a His-Phe-Arg-Trp (HFRW) sequence, critical for binding and activation of MCRs (Dores et al., 2016; Schwyzer, 1977). We used this motif to align the various POMC peptides of the different taxonomic groups (Figure 6a).

The comparison of $\mathrm{MSH}$ peptides between groups supported our taxonomic grouping of phylogenetic clusters. First, in agreement with previously described differences (Dores, Cameron, Lecaude, \& Danielson, 2003; Takahashi, Amemiya, Nozaki, Sower, \& Kawauchi, 2001), the $\delta$-MSH sequence is detected only in species of Group 2 (7/7 species) (Figure 6a and Table S4). Second, $\gamma$-MSH exists in cartilaginous fish and tetrapods, but is absent in the agnathan $\mathrm{POC}$ and POM (Amemiya, Takahashi, Suzuki, Sasayama, \& Kawauchi, 1999) (Figure 6a and Table S4). In agreement with previous studies (Dores \& Baron, 2011; Kitahara et al., 1988), we found $\gamma$-MSH is also absent from Groups 6, 7 and 8. Novel is that $\gamma$-MSH in Squamata is missing in the lineage giving rise to snakes (4/4 species), but is present in lineages from which lizards and geckos arose (4/4 species) (Figure $6 a$ and Table S4). Further, we find mutations in the functionally relevant HFRW motif of $\gamma$-MSH in species from Groups 4 and 5 [e.g., HFHW (1/2 species) and HFRS (2/2 species), respectively) (Figure 6a and Table S4), which may result in non-functional peptides. Together, our analysis suggests that while $\gamma$-MSH was lost in teleosts and snakes, it may already have become non-functional earlier in evolution (Chondrostei and Holostei lineages).

The analysis of ACTH/ $\alpha-M S H$ sequences between the agnathan POC/POM and gnathostome POMC indicates an association with the ability to background-adapt. The $\alpha-\mathrm{MSH}$ sequence is similar in length (13 a.a.) and homology (identity between $92 \%$ and 100\%; 12/13 and 13/13 a.a., respectively) only between groups that background-adapt (Groups 2 to 16 ), but is remarkably different in cyclostomes (Figure 6b). These differences in cyclostome $\alpha-\mathrm{MSH}$ may explain the lack of background adaptation in lamprey. First, while the $\alpha-\mathrm{MSH}$ peptide predicted from the POM gene is identical to the MSH-B peptide isolated from the pituitary glands of the Sea lamprey Petromyzon marinus (Takahashi et al., 1995), it is longer than gnathostome $\alpha-\mathrm{MSH}$, with additional a.a. located near two amino terminal basic a.a. essential for endopeptidase cleavage (Figure 6b). Second, the homology in the region surrounding HFRW is low in agnathans (62\%; $8 / 13$ a.a. as compared to more than $92 \%$ in gnathostomes) (Figure 6b). Finally, the affinity of $\alpha$ MSH to the lamprey Mcr1 is 1,300 times lower than to the human receptor (Haitina et al., 2007; Schiöth, Petersson, Muceniece, Szardenings, \& Wikberg, 1997). The fact that $\alpha-\mathrm{MSH}$ and ACTH bind to the lamprey receptor with similar affinities, while the affinity of $\alpha-\mathrm{MSH}$ for the human MCR1 is 20 times higher than that of ACTH (Haitina et al., 2007; Schiöth et al., 1997), suggests that ACTH may be the biological and the "ancestral" ligand for the Mcr1 in agnathans. Interestingly, the localization of $\alpha-\mathrm{MSH}$ and $\mathrm{ACTH}$ to the intermedia and anterior pituitary, respectively, is nonetheless conserved between agnathans and gnathostomes (Nozaki, Takahashi, Amemiya, Kawauchi, \& Sower, 1995), as is the tetrapeptide HFRW required to bind Mcr1 (Figure 6b) (Costa et al., 2004; Schwyzer, 1977).

As mentioned, species of Groups 2 to 16 all show background adaptation. The literature supports the idea that this pigmentation response associates with the conservation of $\alpha$-MSH sequence between these groups. Particularly relevant in this regard, given their evolutionary separation from mammals, are Group 2 species, which also lack MCHL. The dogfish Squalus acanthias $\alpha-\mathrm{MSH}$ (Figure 6b) (Lowry, Bennett, \& McMartin, 1974) is almost identical to that of human (identity 12/13 a.a; Figure 6b). Interestingly, in sharks, background adaptation is reversed by intravenous administration of $\alpha$-MSH antibodies (Rodrigues \& Sumpter, 1984), and the marine elasmobranch and mammalian $\alpha-\mathrm{MSH}$ both induce melanosome dispersion after intravenous injection (Sumpter \& Lowry, 1984). Indeed, $\alpha$-MSH regulates pigmentation in species from Groups 2 (Potamotrygon reticulatus) (Visconti \& de L. Castrucci, 1993) to Group 16 (Abdel-Malek et al., 1995), suggesting a conserved role (supporting references in Table S1).

Of note, while $\alpha-\mathrm{MSH}$ functions in background adaptation in homoeotherms (Groups 15-16), the peptide source may differ in key ways from that in Groups $10-14$. In birds, $\alpha-\mathrm{MSH}$ is likely produced in a paracrine manner in the integument, and not from the pars intermedia pituitary, which birds lack (Boswell \& Takeuchi, 2005). In mammals, $\alpha-M S H$ levels change seasonally, rising during spring/summer and decreasing in autumn/winter (Altmeyer, Stöhr, \& Holzmann, 1986; Lincoln \& Baker, 1995; McFarlane et al., 2011), but the mechanisms and the source of $\alpha-\mathrm{MSH}$ are unknown. A possible explanation for the differences with Groups 10-14 is that species therein require rapid colour plasticity for thermoregulation (Fan, Stuart-Fox, \& Cadena, 2014; Tattersall, Eterovick, \& Andrade, 2006), a need minimized in birds and mammals with an "insulated" integument.

In summary, our analysis reveals that $\alpha-\mathrm{MSH}$ (and $\beta-\mathrm{MSH}$ ) was conserved during evolution, while $\gamma$-MSH and $\delta$-MSH were not. Interestingly, the differences in $\alpha-\mathrm{MSH}$ a.a. sequence between agnathans and gnathostomes associate with the capacity to background-adapt. In ectotherms, background adaptation (and thermoregulation) is regulated by $\alpha-\mathrm{MSH}$ secreted from the pars intermedia pituitary. In homoeotherms, however, a role of a pituitary-derived $\alpha-\mathrm{MSH}$ in background adaptation is unclear.

\section{5 | Genetic basis and hormonal status underlie differences in background adaptation mechanisms}

We used both the structure and presence of pomc, pmch and pmchl as a "genetic basis," alongside $\mathrm{MCH} / \mathrm{MCHL}$ "hormonal status," to explain differences in the physiological mechanisms for background adaptation over evolution. The genetic basis includes a conserved $\alpha-\mathrm{MSH}$ sequence and function between Groups 2 and 16, but not 


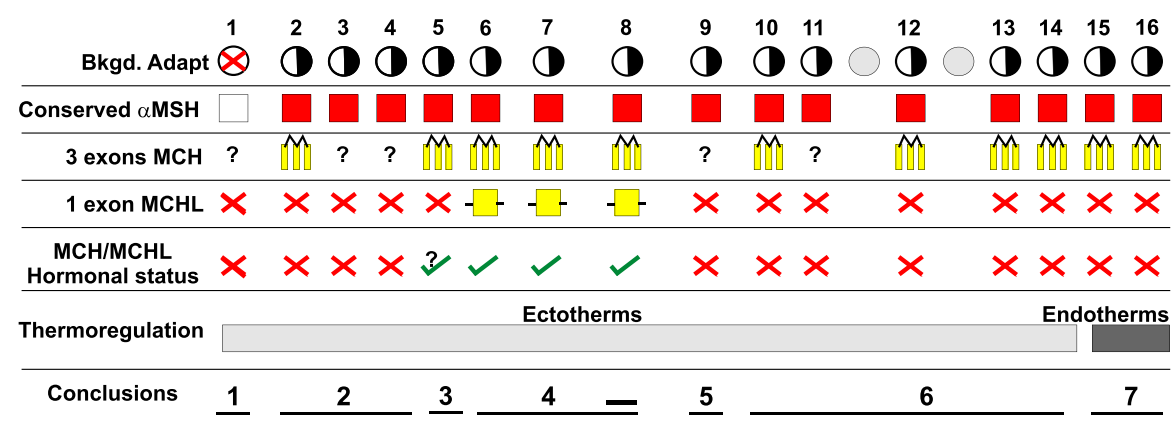

FIGURE 7 Genetics and the hormonal status of MCHL explain the different mechanisms for background adaptation. Groups able to background-adapt are indicated with a white/black circle. The genetic basis corresponds to the presence of a highly conserved 13-a.a. $\alpha$ MSH (red square), a three-exon pmch gene (three yellow bars) or a one-exon pmchl gene (yellow square), while hormonal status indicates the capacity of an $\mathrm{MCH}$ to be released into the bloodstream. A teleost-specific pmchl gene encodes $\mathrm{MCHL}$, which acts as a hormone in background adaptation, while the conserved pmch gene encodes $\mathrm{MCH}$, which we suggest acts as a neurotransmitter to regulate energy homoeostasis and food intake. The six different mechanisms for background adaptation include the following: (a) Group 1: no significant role for $\alpha-\mathrm{MSH}$ and $\mathrm{MCH}$; (b) Groups 2 to 4: $\alpha-\mathrm{MSH}$ but not MCH participates; (c) Group 5: hormonal status appears with a dual role of $\alpha-\mathrm{MSH}$ and $\mathrm{MCH}$ in regulating skin pigmentation; (d) Groups 6-8: a "dual control theory" mechanism for background adaptation at the bottom of Teleostei lineage (Groups 6 and 7) and a single main regulator, likely MCHL, at the top (Group 8); (e) Group 9: $\alpha-\mathrm{MSH}$ but not MCH regulates background adaptation; (f) Groups 10-14: a uni-humoral $\alpha-\mathrm{MSH}$ system that also is involved in thermoregulation; and (g) Groups 15 and 16 : $\alpha-\mathrm{MSH}$ and $\mathrm{MCH}$ roles changed in homoeotherms as insulation systems (fur and feathers) appear during the evolution of endothermy

Group 1 (Figure 7). A conserved three-exon pmch gene, whose function appears conserved and relates to feeding behaviours and energy homoeostasis, is present in species of all 16 Groups. A pmchl gene appears in teleosts (Groups 6-8) and associates with hormonal status for MCHL (Figure 7) and axon projections from pmchl+, but not pmch+, neurons to the hypophysis. Therefore, we suggest MCHL arose evolutionarily in the Teleostei lineage, acquiring hormonal status and a new role in skin pigmentation. Finally, the "genetic basis" and the "hormonal status" together explain the following differences in the mechanisms that regulate background adaptation in vertebrates (Figure 7; conclusions):

1. Group 1: No significant role for $\alpha-\mathrm{MSH}$ and $\mathrm{MCH}$. The absence of a background adaptation response in cyclostomes likely reflects the inability of $\mathrm{MCH}$ and $\alpha-\mathrm{MSH}$ to regulate skin pigment dispersion or aggregation, with a distinct $\alpha$-MSH sequence and affinity to Mcr1 from that in gnathostomes. Lamprey skin does not respond to synthetic salmon MCHL (Baker \& Bird, 2002), and a "melanophore-aggregating factor" is detected in hypothalamic but not pituitary extracts (Baker \& Rance, 1983), suggesting that $\mathrm{MCH}$ does not possess hormonal status. Additionally, $\mathrm{MCHL}$ is not present in cyclostomes (Figure 7).

2. Groups 2-4: $\alpha-\mathrm{MSH}$ but not $\mathrm{MCH}$ regulates background adaptation. $\mathrm{MCHL}$ is not detected in these groups, and $\mathrm{MCH}$ does not appear to have hormonal status. For instance, a shark $\mathrm{MCH}$ antibody detects cells in the hypothalamus, but not the pituitary gland, of Sphyrna lewini (Group 2) (Mizusawa et al., 2012). Additionally, neither human $\mathrm{MCH}$ (95\% identity to shark $\mathrm{MCH}$; 18/19 a.a.), nor synthetic MCHL, produce aggregation in Triakis scyllium and Potamotrygon reticulatus (Group 2) (Mizusawa et al., 2012; Visconti \& de L. Castrucci, 1993). Yet, pituitary-derived $\alpha$ $\mathrm{MSH}$ regulates background adaptation in several shark species
(Visconti \& de L. Castrucci, 1993) (Figure 7; supporting references in Table S1). Interestingly, skin melanophores from Erpetoichthys calabaricus (Group 3), and Acipenser stellate and Polyodon spathula (Group 4), do not respond to synthetic $\mathrm{MCH}$ and $\mathrm{MCHL}$, and $\mathrm{MCH}$ antibodies fail to label fibres in the posterior pituitary (Baker \& Bird, 2002; Sherbrooke \& Hadley, 1988), arguing against hormonal status for $\mathrm{MCH}$ in Groups 3 and 4. Background adaptation in species from these groups, however, requires a functional pituitary and involves $\alpha-\mathrm{MSH}$-induced dispersion of melanosomes, pointing to $\alpha-\mathrm{MSH}$, but not $\mathrm{MCH}$, as the key regulator of skin pigmentation (Figure 7 and additional references in Table S1).

3. Group 5: Hormonal status and skin response to $\mathrm{MCH}$ appears. In holosteans, $\mathrm{MCH}+$ fibres extend to the pituitary in Lepisosteus osseus and Amia calva, and MCHL causes melanosome aggregation (Baker \& Bird, 2002; Sherbrooke \& Hadley, 1988). Therefore, a dual hormonal role of $\alpha-\mathrm{MSH}$ and $\mathrm{MCH}$ in regulating skin pigmentation is possible. Whether $\mathrm{MCHL}$ is responsible is unclear, in that we were unable to find $p c m h l$ in any holostean genome, including that of the fully sequenced Lepisosteus oculatus (Figure 7). Thus, it is possible that the dualhormonal system was present in the common ancestor of holosteans and teleosts. A key question that needs to be addressed is what selective advantage, if any, was provided by the duplicated genes of teleosts? Evolutionary selection of pmchl may be explained as a case of subfunctionalization, with essentially no functional change before and after the duplication in holosteans.

4. Groups 6-8: A dual control mechanism at the bottom of the Teleostei lineage (Groups 6 and 7), and a single main regulator, likely $\mathrm{MCHL}$, at the top (Group 8). We suggest $\mathrm{pcmhl}$ appears early in the teleost lineage by retroposition or during the TSD, with $\mathrm{MCHL}$-expressing neurons then selected over evolution to extend 
their axons to the pituitary. In this manner, function was split between neurotransmitter $(\mathrm{MCH})$ and hormonal $(\mathrm{MCHL})$ roles. In support of the dual control theory in Groups 6 and 7, physiological changes in both $\alpha-\mathrm{MSH}$ (black background) and MCHL (white background) are produced when background is altered. For example, in the eel (Group 7), MCH induces melanosome aggregation, and a salmon MCHL antibody labels secretory granules in neurons with fibres that terminate on neurohypophysial blood vessels, whose density varies between white and black adapted organisms (Gilham \& Baker, 1984; Powell \& Baker, 1988). Plasma $\alpha-M S H$ levels increase in eels with a black background (Baker et al., 1984). In zebrafish, in addition to the hormonal status for MCHL suggested by our expression analysis (Figure 2), a white background increases pmchl mRNA levels, while fasting increases the expression of pmch (Berman et al., 2009). A black background in zebrafish triggers melanosome dispersion via $\alpha-\mathrm{MSH}$ interaction with Mcr1 expressed by melanophores (Richardson et al., 2008). In two Group 8 species, Starry flounder (Platichthys stellatus (Kang \& Kim, 2013)) and Barfin flounder (Verasper moseri (Mizusawa et al., 2015)), pmch and pmchl mRNAs increase in white backgroundadapted organisms, although most robustly for pmchl. Because $\mathrm{MCHL}$, but not pomc mRNA/ $\alpha-\mathrm{MSH}$, levels change with background in several Group 8 species at the top of the Teleostei lineage, it is possible that during evolution the balance between $\alpha-\mathrm{MSH}$ and $\mathrm{MCH}$ changed from $\alpha-\mathrm{MSH} » \mathrm{MCH}$ in Groups $2-4$, to a dual mechanism in Groups 6 and $7(\alpha-\mathrm{MSH}=\mathrm{MCH} 2)$, to $\alpha$ $\mathrm{MSH} \ll \mathrm{MCHL}$ in Group 8 species (Figure 7).

5. Group 9: $\alpha-\mathrm{MSH}$ but not $\mathrm{MCH}$ regulates background adaptation. $\mathrm{MCH}+$ nerve fibres are absent from the neural lobe of the pituitary of Protopterus annectens, and synthetic salmonid MCHL does not influence skin cells of Lepidosiren paradoxa (Dipnoi) (Baker, 1991; Visconti \& de L. Castrucci, 1993), suggesting that $\mathrm{MCH}$ does not have hormonal status and plays no role in skin pigmentation (Figure 7).

6. Groups 10-14: A uni-humoral $\alpha-\mathrm{MSH}$ control system for background adaptation and thermoregulation. $\mathrm{MCHL}$ is not present in amphibians and reptiles, and $\mathrm{MCH}$ appears to lack hormonal status (Figure 7). Indeed, while the hypothalamus contains $\mathrm{MCH}$-expressing cells in frogs (Rana esculenta; Group 10), Squamata (Podarcis muralis and Natrix natrix; Group 12) and turtles (Trachemys scripta; Group 13), their axons do not project to the posterior pituitary (Cardot et al., 1994; Lázár et al., 2002). Thus, $\alpha-M S H$ is the main regulator of background adaptation and may also be important for temperature regulation of ectotherms though colour plasticity (Fernandez \& Bagnara, 1991).

7. Groups 15 and 16 : New roles for $\alpha-\mathrm{MSH}$ and $\mathrm{MCH}$. In birds and mammals, $\mathrm{MCHL}$ does not exist, $\mathrm{MCH}+$ cells do not extend axons to the pituitary (Cardot et al., 1999; Cortés et al., 2014), and the pars intermedia pituitary disappears in birds, arguing against a hormonal status for $\mathrm{MCH}$ (Figure 7). Birds rely on carotenoid ingestion for background adaptation, while in mammals $\alpha-\mathrm{MSH}$ possibly associates with seasonal colour moulting. Thus, while colour plasticity is important for thermoregulation in ectotherms, in feather/hair covered homoeotherms, skin pigment cells changed with regard to cell type (only melanocytes in birds and mammals), pigment type (eumelanin and pheomelanin) and properties (pigment secretion vs. dispersion/aggregation).

Together, our experimental data and comparison of evolutionary studies suggest that $\mathrm{MCHL}$ but not $\mathrm{MCH}$ has hormonal status in teleosts. A conserved $\alpha$-MSH peptide and the presence of $\mathrm{MCH}$ or $\mathrm{MCHL}$ constitute the "genetic basis" for background adaptation that together with the "hormonal status" for MCHL explains the different background adaptation mechanisms observed in vertebrates.

\section{ACKNOWLEDGEMENTS}

This work was supported by an operating grant from the Natural Sciences and Engineering Research Council of Canada to SM, and a BioTalent Canada award to JZZ. We thank Risa Mori-Kreiner and Drs. K. Atkinson-Leadbeater and Joel B. Dacks for helpful comments on the manuscript.

\section{CONFLICT OF INTEREST}

The authors declare no conflict of interest.

\section{AUTHOR CONTRIBUTIONS}

GEB designed the experiments. GEB and JZZ performed the experiments and analysed the data. GEB and SM wrote the paper.

\section{ORCID}

Gabriel E. Bertolesi (iD https://orcid.org/0000-0001-6154-9513

\section{REFERENCES}

Abdel-Malek, Z., Swope, V. B., Suzuki, I., Akcali, C., Harriger, M. D., Boyce, S. T., ... Hearing, V. J. (1995). Mitogenic and melanogenic stimulation of normal human melanocytes by melanotropic peptides. Proceedings of the National Academy of Sciences, 92, 1789-1793. https://doi. org/10.1073/pnas.92.5.1789

Altmeyer, P., Stöhr, L., \& Holzmann, H. (1986). Seasonal rhythm of the plasma level of alpha-melanocyte stimulating hormone. The Journal of Investigative Dermatology, 86, 454-456. https://doi. org/10.1111/1523-1747.ep12285798

Amano, M., \& Takahashi, A. (2009). Melanin-concentrating hormone: A neuropeptide hormone affecting the relationship between photic environment and fish with special reference to background color and food intake regulation. Peptides, 30, 1979-1984. https://doi. org/10.1016/j.peptides.2009.05.022

Amemiya, Y., Takahashi, A., Suzuki, N., Sasayama, Y., \& Kawauchi, H. (1999). A Newly characterized melanotropin in proopiomelanocortin in pituitaries of an elasmobranch, Squalus acanthias. General and Comparative Endocrinology, 114, 387-395. https://doi.org/10.1006/ gcen.1999.7256

Audinot, V., Beauverger, P., Lahaye, C., Suply, T., Rodriguez, M., Ouvry, C., ... Boutin, J. A. (2001). Structure-activity relationship studies of melanin-concentrating hormone $(\mathrm{MCH})$-related peptide ligands at 
SLC-1, the human MCH receptor. Journal of Biological Chemistry, 276, 13554-13562. https://doi.org/10.1074/jbc.M010727200

Babák, E. (1910). Zur chromatischen Hautfunktion der Amphibien. Pflüger, Archiv Für Die Gesammte Physiologie Des Menschen Und Der Thiere, 131, 87-118. https://doi.org/10.1007/BF01688797

Baker, B. I. (1991). Melanin-concentrating hormone: A general vertebrate neuropeptide. International Review of Cytology, 126, 1-47. https://doi. org/10.1016/s0074-7696(08)60681-6

Baker, B. I. (1993). The role of melanin-concentrating hormone in color change. Annals of the New York Academy of Sciences, 680, 279-289. https://doi.org/10.1111/j.1749-6632.1993.tb19690.x

Baker, B. I., \& Bird, D. J. (2002). Neuronal organization of the melanin-concentrating hormone system in primitive actinopterygians: Evolutionary changes leading to teleosts. The Journal of Comparative Neurology, 442, 99-114. https://doi.org/10.1002/cne.10074

Baker, B., Levy, A., Hall, L., \& Lightman, S. (1995). Cloning and expression of melanin-concentrating hormone genes in the rainbow trout brain. Neuroendocrinology, 61, 67-76. https://doi.org/10.1159/000126814

Baker, B. I., \& Rance, T. A. (1983). Further observations on the distribution and properties of teleost melanin concentrating hormone. General and Comparative Endocrinology, 50, 423-431. https://doi. org/10.1016/0016-6480(83)90263-0

Baker, B. I., Wilson, J. F., \& Bowley, T. J. (1984). Changes in pituitary and plasma levels of $\mathrm{MSH}$ in teleosts during physiological colour change. General and Comparative Endocrinology, 55, 142-149. https://doi. org/10.1016/0016-6480(84)90138-2

Beltran, R. S., Burns, J. M., \& Breed, G. A. (2018). Convergence of biannual moulting strategies across birds and mammals. Proceedings of the Royal Society B-Biological Sciences, 285, 20180318. https://doi. org/10.1098/rspb.2018.0318

Berman, J. R., Skariah, G., Maro, G. S., Mignot, E., \& Mourrain, P. (2009) Characterization of two melanin-concentrating hormone genes in zebrafish reveals evolutionary and physiological links with the mammalian MCH system. The Journal of Comparative Neurology, 517, 695710. https://doi.org/10.1002/cne.22171

Bertolesi, G. E., Hehr, C. L., \& Mcfarlane, S. (2015). Melanopsin photoreception in the eye regulates light-induced skin colour changes through the production of $\alpha-\mathrm{MSH}$ in the pituitary gland. Pigment Cell \& Melanoma Research, 28, 559-571. https://doi.org/10.1111/ pcmr.12387

Bertolesi, G. E., \& McFarlane, S. (2018). Seeing the light to change colour: An evolutionary perspective on the role of melanopsin in neuroendocrine circuits regulating light-mediated skin pigmentation. Pigment Cell \& Melanoma Research, 31, 354-373. https://doi.org/10.1111/ pcmr.12678

Betancur-R, R., Broughton, R. E., Wiley, E. O., Carpenter, K., López, J. A., Li, C., ... Ortí, G. (2013). The tree of life and a new classification of bony fishes. PLOS Currents Tree of Life. https://doi.org/ 10.1371/ currents.tol.53ba26640df0ccaee75bb165c8c26288

Betancur-R, R., Wiley, E. O., Arratia, G., Acero, A., Bailly, N., Miya, M., ... Ortí, G. (2017). Phylogenetic classification of bony fishes. BMC Evolutionary Biology, 17, 162. https://doi.org/10.1186/ s12862-017-0958-3

Bittencourt, J., \& Celis, M. E. (2008). Anatomy, function and regulation of neuropeptide El (NEI). Peptides, 29, 1441-1450. https://doi. org/10.1016/j.peptides.2008.03.012

Boswell, T., \& Takeuchi, S. (2005). Recent developments in our understanding of the avian melanocortin system: Its involvement in the regulation of pigmentation and energy homeostasis. Peptides, 26, 1733-1743. https://doi.org/10.1016/j.peptides.2004.11.039

Braasch, I., Brunet, F., Volff, J. N., \& Schartl, M. (2010). Pigmentation pathway evolution after whole-genome duplication in fish. Genome Biology and Evolution, 1, 479-493. https://doi.org/10.1093/gbe/evp050

Breton, C., Presse, F., Hervieu, G., \& Nahon, J. L. (1993). Structure and regulation of the mouse melanin-concentrating hormone mRNA and gene. Molecular and Cellular Neurosciences, 4, 271-284. https://doi. org/10.1006/mcne.1993.1035

Cardot, J., Fellmann, D., \& Bugnon, C. (1994). Melanin-concentrating hormone-producing neurons in reptiles. General and Comparative Endocrinology, 94, 23-32. https://doi.org/10.1006/gcen.1994.1056

Cardot,J.,Griffond,B.,Risold,P.Y.,Blähser,S.,\&Fellmann,D.(1999).Melaninconcentrating hormone-producing neurons in birds. The Journal of Comparative Neurology, 411, 239-256. https://doi.org/10.1002/ (SICI)1096-9861(19990823)411:2<239:AID-CNE5>3.0.CO;2-7

Cortés, R., Navarro, S., Agulleiro, M. J., Guillot, R., García-Herranz, V., Sánchez, E., \& Cerdá-Reverter, J. M. (2014). Evolution of the melanocortin system. General and Comparative Endocrinology, 209, 3-10. https://doi.org/10.1016/j.ygcen.2014.04.005.

Costa, J. L., Bui, S., Reed, P., Dores, R. M., Brennan, M. B., \& Hochgeschwender, U. (2004). Mutational analysis of evolutionarily conserved ACTH residues. General and Comparative Endocrinology, 136, 12-16. https://doi.org/10.1016/j.ygcen.2003.11.005

Courseaux, A., \& Nahon, J.-L. (2001). Birth of two chimeric genes in the hominidae lineage. Science, 291:1293-1297.

Cui, L., Lv, C., Zhang, J., Mo, C., Lin, D., Li, J., \& Wang, Y. (2017). Characterization of melanin-concentrating hormone $(\mathrm{MCH})$ and its receptor in s: Tissue expression, functional analysis, and fasting-induced up-regulation of hypothalamic $\mathrm{MCH}$ expression. Gene, 615, 57-67.

de Rijk, E. P., Jenks, B. G., \& Wendelaar Bonga, S. E. (1990), Morphology of the pars intermedia and the melanophore-stimulating cells in Xenopus laevis in relation to background adaptation. General and Comparative Endocrinology, 79, 74-82. https://doi. org/10.1016/0016-6480(90)90089-5

Dores, R. M., \& Baron, A. J. (2011). Evolution of POMC: Origin, phylogeny, posttranslational processing, and the melanocortins. Annals of the New York Academy of Sciences, 1220, 34-48. https://doi. org/10.1111/j.1749-6632.2010.05928.x

Dores, R. M., Cameron, E., Lecaude, S., \& Danielson, P. B. (2003). Presence of the delta-MSH sequence in a proopiomelanocortin cDNA cloned from the pituitary of the galeoid shark, Heterodontus portusjacksoni. General and Comparative Endocrinology, 133, 71-79. https://doi.org/10.1016/s0016-6480(03)00151-5

Dores, R. M., Liang, L., Davis, P., Thomas, A. L., \& Petko, B. (2016). 60 YEARS OF POMC: Melanocortin receptors: Evolution of ligand selectivity for melanocortin peptides. Journal of Molecular Endocrinology, 56, T119-T133. https://doi.org/10.1530/JME-15-0292

Enami, M. (1955). Melanophore-contracting hormone (MCH) of possible hypothalamic origin in the catfish, Parasilurus. Science, 121, 36-37. https://doi.org/10.1126/science.121.3132.36

Eterovick, P. C., Mendes, I. S., Kloh, J. S., Pinheiro, L. T., Václav, A. B. H. P., Santos, T., \& Gontijo, A. S. B. (2018). Tadpoles respond to background colour under threat. Scientific Reports, 8, 4085. https://doi. org/10.1038/s41598-018-22315-8

Fan, M., Stuart-Fox, D., \& Cadena, V. (2014). Cyclic colour change in the bearded dragon Pogona vitticeps under different photoperiods. PLoS ONE, 9, e111504. https://doi.org/10.1371/journal.pone. 0111504

Fernandez, P. J., \& Bagnara, J. T. (1991). Effect of background color and low temperature on skin color and circulating alpha-MSH in two species of leopard frog. General and Comparative Endocrinology, 83, 132-141. https://doi.org/10.1016/0016-6480(91)90113-k

Ferroni, E. N., \& Castrucci, A. M. (1987). Alpha-MSH (melanocyte stimulating hormone) and $\mathrm{MCH}$ (melanin concentrating hormone) actions in Bufo ictericus ictericus melanophores. Comparative Biochemistry and Physiology, A: Comparative Physiology, 88, 15-20.

Fujimoto, M., Fukuda, S., Sakamoto, H., Takata, J., \& Sawamura, S. (2017). Neuropeptide glutamic acid-isoleucine (NEI)-induced paradoxical sleep in rats. Peptides, 87, 28-33. https://doi.org/10.1016/j. peptides.2016.11.007 
Gilham, I. D., \& Baker, B. I. (1984). Evidence for the participation of a melanin-concentrating hormone in physiological colour change in the eel. Journal of Endocrinology, 102, 237-243. https://doi.org/10.1677/ joe.0.1020237

Gröneveld, D., Balm, P. H., Martens, G. J., \& Wendelaar Bonga, S. E. (1995a). Differential melanin-concentrating hormone gene expression in two hypothalamic nuclei of the teleost tilapia in response to environmental changes. Journal of Neuroendocrinology, 7, 527-533. https://doi.org/10.1111/j.1365-2826.1995.tb00789.x

Gröneveld, D., Balm, P. H., \& Wendelaar Bonga, S. E. (1995b). Biphasic effect of $\mathrm{MCH}$ on alpha-MSH release from the tilapia (Oreochromis mossambicus) pituitary. Peptides, 16, 945-949.

Gröneveld, D., Balm, P. H. M., \& Wendelaar Bonga, S. E. (1995c). Identification, cellular localization and in vitro release of a novel teleost melanin-concentrating hormone gene-related peptide. Neuroendocrinology, 62, 498-505.

Haitina, T., Klovins, J., Takahashi, A., Löwgren, M., Ringholm, A., Enberg, J., ... Schiöth, H. B. (2007). Functional characterization of two melanocortin $(\mathrm{MC})$ receptors in lamprey showing orthology to the MC1 and MC4 receptor subtypes. BMC Evolutionary Biology, 7, 1-14. https://doi.org/10.1186/1471-2148-7-101

Heinig, J. A., Keeley, F. W., Robson, P., Sower, S. A., \& Youson, J. H. (1995). The appearance of proopiomelanocortin early in vertebrate evolution: cloning and sequencing of POMC from a lamprey pituitary cDNA library. General and Comparative Endocrinology, 99, 137-144. https://doi.org/10.1006/gcen.1995.1094

Hoegg, S., Brinkmann, H., Taylor, J. S., \& Meyer, A. (2004). Phylogenetic timing of the fish-specific genome duplication correlates with the diversification of teleost fish. Journal of Molecular Evolution, 59, 190203. https://doi.org/10.1007/s00239-004-2613-z

Hoekstra, H. E. (2006). Genetics, development and evolution of adaptive pigmentation in vertebrates. Heredity, 97, 222-234. https://doi. org/10.1038/sj.hdy.6800861

Hogben, L., \& Slome, D. (1936). The pigmentary effector system. VIII. The dual receptive mechanism of the amphibian background response. Proceedings of the Royal Society of London. Series B - Biological Sciences, 120, 158-173. https://doi.org/10.1098/ rspb.1936.0029

Hu, C. K., Southey, B. R., Romanova, E. V., Maruska, K. P., Sweedler, J. V., \& Fernald, R. D. (2016). Identification of prohormones and pituitary neuropeptides in the African cichlid. Astatotilapia Burtoni. BMC Genomics, 17, 660. https://doi.org/10.1186/s12864-016-2914-9

Jenks, B. G., van Overbeeke, A. P., \& McStay, B. F. (1977). Synthesis, storage, and release of $\mathrm{MSH}$ in the pars intermedia of the pituitary gland of Xenopus laevis during background adaptation. Canadian Journal of Zoology, 55, 922-927. https://doi.org/10.1139/z77-120

Ji, Q., Luo, Z. X., Yuan, C. X., \& Tabrum, A. R. (2006). A swimming mammaliaform from the Middle Jurassic and ecomorphological diversification of early mammals. Science, 311, 1123-1127. https://doi. org/10.1126/science.1123026

Joss, J. M. P. (1973). The pineal complex, melatonin, and color change in the lamprey Lampetra. General and Comparative Endocrinology, 21, 188-195. https://doi.org/10.1016/0016-6480(73)90170-6

Kang, D.-Y., \& Kim, H.-C. (2013). Functional characterization of two melanin-concentrating hormone genes in the color camouflage, hypermelanosis, and appetite of starry flounder. General and Comparative Endocrinology, 189, 74-83. https://doi.org/10.1016/j. ygcen.2013.04.025

Kawauchi, H. (2006). Functions of melanin-concentrating hormone in fish. Journal of Experimental Zoology Part A: Comparative Experimental Biology, 305A, 751-760. https://doi.org/10.1002/jez.a.310

Kawauchi, H., Kawazoe, I., Tsubokawa, M., Kishida, M., \& Baker, B. I. (1983). Characterization of melanin-concentrating hormone in chum salmon pituitaries. Nature, 305, 321-323. https://doi. org/10.1038/305321a0
Kinoshita, M., Morita, T., Toyohara, H., Hirata, T., Sakaguchi, M., Ono, M., ... Ozato, K. (2001). Transgenic medaka overexpressing a melanin-concentrating hormone exhibit lightened body color but no remarkable abnormality. Marine Biotechnology, 3, 536-543. https://doi. org/10.1007/s10126-001-0061-Y

Kishida, M., Baker, B. I., \& Eberle, A. N. (1989). The measurement of melanin-concentrating hormone in trout blood solid-phase. General and Comparative Endocrinology, 4, 221-229. https://doi. org/10.1016/0016-6480(89)90216-5

Kitahara, N., Nishizawa, T., lida, K., Okazaki, H., Andoh, T., \& Soma, G. I. (1988). Absence of a gamma-melanocyte-stimulating hormone sequence in proopiomelanocortin mRNA of chum salmon Oncorhynchus keta. Comparative Biochemistry and Physiology Part B, 91, 365-370.

Klovins, J., Haitina, T., Fridmanis, D., Kilianova, Z., Kapa, I., Fredriksson, R., ... Schiöth, H. B. (2004). The melanocortin system in fugu: determination of POMC/AGRP/MCR gene repertoire and synteny, as well as pharmacology and anatomical distribution of the MCRs. Molecular Biology and Evolution, 21, 563-579. https://doi.org/10.1093/molbev/ msh050

Kumar, S., Stecher, G., Li, M., Knyaz, C., \& Tamura, K. (2018). MEGA X: Molecular evolutionary genetics analysis across computing platforms. Molecular Biology and Evolution, 35, 1547-1549. https://doi. org $/ 10.1093 / \mathrm{molbev} / \mathrm{msy} 096$

Lázár, G., Maderdrut, J. L., \& Merchenthaler, I. (2002). Distribution of melanin-concentrating hormone-like immunoreactivity in the central nervous system of Rana esculenta. Brain Research Bulletin, 57, 401407. https://doi.org/10.1016/S0361-9230(01)00675-X

Leong, J. S., Jantzen, S. G., von Schalburg, K. R., Cooper, G. A., Messmer, A. M., Liao, N. Y., ... Koop, B. F. (2010). Salmo salar and Esox lucius full-length cDNA sequences reveal changes in evolutionary pressures on a post-tetraploidization genome. BMC Genomics, 11, 279. https://doi.org/10.1186/1471-2164-11-279

Liang, L., Reinick, C., Angleson, J. K., \& Dores, R. M. (2013). Evolution of melanocortin receptors in cartilaginous fish: Melanocortin receptors and the stress axis in elasmobranches. General and Comparative Endocrinology, 181, 4-9. https://doi.org/10.1016/j. ygcen.2012.08.016

Lien, S., Koop, B. F., Sandve, S. R., Miller, J. R., Kent, M. P., Nome, T., ... Davidson, W. S. (2016). The Atlantic salmon genome provides insights into rediploidization. Nature, 533, 200-205. https://doi. org/10.1038/nature17164

Lin, S. j., Foley, J., Jiang, T. x., Yeh, C. y., Wu, P., Foley, A., ... Chuong, C. m. (2013). Topology of feather melanocyte progenitor niche allows complex pigment patterns to emerge. Science, 31, 1713-1723. https://doi.org/10.1126/science.1230374

Lincoln, G. A., \& Baker, B. I. (1995). Seasonal and photoperiod-induced changes in the secretion of a-melanocyte-stimulating hormone in Soay sheep: Temporal relationship with changes in b-endorphin, prolactin, follicle-stimulating hormone, activity of the gonads and growth of wool and horns. Journal of Endocrinology, 144, 471-481. https://doi.org/10.1677/joe.0.1440471

Linnen, C. R., Poh, Y.-P., Peterson, B. K., Barrett, R. D. H., Larson, J. G., Jensen, J. D., \& Hoekstra, H. E. (2013). Adaptive evolution of multiple traits through multiple mutations at a single gene. Science, 339, 1312-1316. https://doi.org/10.1126/science.1233213

Lorin, T., Brunet, F. G., Laudet, V., \& Volff, J.-N. (2018). Teleost fish-specific preferential retention of pigmentation gene-containing families after whole genome duplications in vertebrates. Genes|genomes|genetics, 8(5), 1795-1806. https://doi.org/10.1534/g3.118.200201

Lovegrove, B. G. (2017). A phenology of the evolution of endothermy in birds and mammals. Biological Reviews, 92, 1213-1240. https://doi. org/10.1111/brv.12280

Lowe, C., \& Goodman-Lowe, G. (1996). Suntanning in hammerhead sharks. Nature, 383, 677. https://doi.org/10.1038/383677a0 
Lowry, P. J., Bennett, H. P., \& McMartin, C. (1974). The isolation and amino acid sequence of an adrenocorticotrophin from the pars distalis and a corticotrophin-like intermediate-lobe peptide from the neurointermediate lobe of the pituitary of the dogfish Squalus acanthias. The Biochemical Journal, 141, 427-437.

Ludwig, D. S., Tritos, N. A., Mastaitis, J. W., Kulkarni, R., Kokkotou, E., Elmquist, J., ... Maratos-Flier, E. (2001). Melanin-concentrating hormone overexpression in transgenic mice leads to obesity and insulin resistance. Journal of Clinical Investigation, 107, 379-386. https://doi. org/10.1172/JCl10660

Matsuda, K., Shimakura, S.-I., Miura, T., Maruyama, K., Uchiyama, M., Kawauchi, H., ... Takahashi, A. (2007). Feeding-induced changes of melanin-concentrating hormone $(\mathrm{MCH})$-like immunoreactivity in goldfish brain. Cell and Tissue Research, 328, 375-382. https://doi. org/10.1007/s00441-006-0347-5

Matsunaga, T. O., Hruby, V. J., Lebl, M., Castrucci, A. M., \& Hadley, M. E. (1992). Synthesis and bioactivity studies of two isosteric acyclic analogues of melanin concentrating hormone. Life Sciences, 51, 679-685. https://doi.org/10.1016/0024-3205(92)90241-G

McFarlane, D., Paradis, M. R., Zimmel, D., Sykes, B., Brorsen, B. W., Sanchez, A., \& Vainio, K. (2011). The effect of geographic location, breed, and pituitary dysfunction on seasonal adrenocorticotropin and $\alpha$-melanocyte-stimulating hormone plasma concentrations in horses. Journal of Veterinary Internal Medicine, 25, 872-881. https:// doi.org/10.1111/j.1939-1676.2011.0745.x

Minth, C. D., Qiu, H., Akil, H., Watson, S. J., \& Dixon, J. E. (1989). Two precursors of melanin-concentrating hormone: DNA sequence analysis and in situ immunochemical localization. Proceedings of the National Academy of Sciences, 86, 4292-4296. https://doi.org/10.1073/pnas.86.11.4292

Mizusawa, K., Amiya, N., Yamaguchi, Y., Takabe, S., Amano, M., Breves, J. P., ... Takahashi, A. (2012). Identification of mRNAs coding for mammalian-type melanin-concentrating hormone and its receptors in the scalloped hammerhead shark Sphyrna lewini. General and Comparative Endocrinology, 179, 78-87. https://doi.org/10.1016/j. ygcen.2012.07.023

Mizusawa, K., Kawashima, Y., Sunuma, T., Hamamoto, A., Kobayashi, Y., Kodera, Y., ... Takahashi, A. (2015). Involvement of melanin-concentrating hormone 2 in background color adaptation of barfin flounder Verasper moseri. General and Comparative Endocrinology, 214, 140148. https://doi.org/10.1016/j.ygcen.2014.07.008

Mizusawa, K., Kobayashi, Y., Sunuma, T., Asahida, T., Saito, Y., \& Takahashi, A. (2011). Inhibiting roles of melanin-concentrating hormone for skin pigment dispersion in barfin flounder, Verasper moseri. General and Comparative Endocrinology, 171, 75-81. https://doi.org/10.1016/j. ygcen.2010.12.008

Mizusawa, K., Kobayashi, Y., Yamanome, T., Saito, Y., \& Takahashi, A. (2013). Interrelation between melanocyte-stimulating hormone and melanin-concentrating hormone in physiological body color change: Roles emerging from barfin flounder Verasper moseri. General and Comparative Endocrinology, 181, 229-234.

Nahon, J. L., Presse, F., Bittencourt, J. C., Sawchenko, P. E., \& Vale, W. (1989). The rat melanin-concentrating hormone messenger ribonucleic acid encodes multiple putative neuropeptides coexpressed in the dorsolateral hypothalamus. Endocrinology, 125, 2056-2065. https://doi.org/10.1210/endo-125-4-2056

Nahon, J.-L., Presset, F., Schoepfer, R., \& Vale, W. (1991). Identification of a single melanin-concentrating hormone messenger ribonucleic acid in coho salmon: Structural relatedness with 7SL ribonucleic acid. Journal of Neuroendocrinology, 3, 173-183. https://doi. org/10.1111/j.1365-2826.1991.tb00260.x

Near, T. J., Eytan, R. I., Dornburg, A., Kuhn, K. L., Moore, J. A., Davis, M. P., ... Smith, W. L. (2012). Resolution of ray-finned fish phylogeny and timing of diversification. Proceedings of the National Academy of Sciences, 109, 13698-13703. https://doi.org/10.1073/ pnas.1206625109
Nozaki, M., Takahashi, A., Amemiya, Y., Kawauchi, H., \& Sower, S. A. (1995). Distribution of lamprey adrenocorticotropin and melanotropins in the pituitary of the adult sea lamprey, Petromyzon marinus. General and Comparative Endocrinology, 98, 147-156. https://doi. org/10.1006/gcen.1995.1055

Okelo, O. (1986). Neuroendocrine control of physiological color change in Chameleo gracilis. General and Comparative Endocrinology, 64, 305-311. https://doi.org/10.1016/0016-6480(86)90018-3

Ono, M., Wada, C., Oikawa, I., Kawazoe, I., \& Kawauchi, H. (1988). Structures of two kinds of mRNA encoding the chum salmon melanin-concentrating hormone. Gene, 71, 433-438. https://doi. org/10.1016/0378-1119(88)90060-1

Parichy, D., \& Spiewak, J. (2015). Origin of adult pigmentation: Diversity of pigment stem cell lineages and implications for pattern evolution. pdf. Pigment Cell Melanoma Res, 28, 31-50.

Powell, K. A., \& Baker, B. I. (1988). Structural studies of nerve terminals containing melanin-concentrating hormone in the eel, Anguilla anguilla. Cell and Tissue Research, 251, 433-439. https://doi. org/10.1007/BF00215852

Price, T., \& Bontrager, A. (2001). Evolutionary genetics: The evolution of plumage patterns. Current Biology, 11, 405-408. https://doi. org/10.1016/S0960-9822(01)00220-2

Prum, R. O., \& Brush, A. H. (2002). The evolutionary origin and diversification of feathers. The Quarterly Review of Biology, 77, 261-295. https://doi.org/10.1086/341993

Richardson, J., Lundegaard, P. R., Reynolds, N. L., Dorin, J. R., Porteous, D. J., Jackson, I. J., \& Patton, E. E. (2008). mc1r pathway regulation of zebrafish melanosome dispersion. Zebrafish, 5, 289-295. https://doi. org/10.1089/zeb.2008.0541

Robbins, L. S., Nadeau, J. H., Johnson, K. R., Kelly, M. A., RoselliRehfuss, L., Baack, E., ... Cone, R. D. (1993). Pigmentation phenotypes of variant extension locus alleles result from point mutations that alter MSH receptor function. Cell, 72, 827-834. https://doi. org/10.1016/0092-8674(93)90572-8

Rodrigues, K. T., \& Sumpter, J. P. (1984). Effects of background adaptation on the pituitary and plasma concentrations of some pro-opiomelanocortin-related peptides in the rainbow trout (Salmo gairdneri). Journal of Endocrinology, 101, 277-284. https://doi.org/10.1677/ joe.0.1010277

Rosenblum, E. B., Hoekstra, H. E., \& Nachman, M. W. (2004). Adaptive reptile color variation and the evolution of the MC1R gene. Evolution, 58, 1794-1808. https://doi.org/10.1554/03-741

Roulin, A., \& Ducrest, A.-L. (2013). Genetics of colouration in birds. Seminars in Cell \& Developmental Biology, 24, 594-608. https://doi. org/10.1016/j.semcdb.2013.05.005

Schiöth, H. B., Petersson, S., Muceniece, R., Szardenings, M., \& Wikberg, J. E. (1997). Deletions of the N-terminal regions of the human melanocortin receptors. FEBS Letters, 410, 223-228. https://doi. org/10.1016/S0014-5793(97)00593-0

Schwyzer, R. (1977). ACTH: A short introductory review. Annals of the New York Academy of Sciences, 297, 3-26. https://doi. org/10.1111/j.1749-6632.1977.tb41843.x

Sherbrooke, W. C., \& Hadley, M. E. (1988). Exploring the evolutionary history of melanin-concentrating and melanin-stimulating hormone receptors on melanophores: Neopterygian (holostean) and chondrostean fishes. Pigment Cell Research, 1, 344-349. https://doi org/10.1111/j.1600-0749.1988.tb00130.x

Skelhorn, J., \& Rowe, C. (2016). Cognition and the evolution of camouflage. Proceedings of the Royal Society B: Biological Sciences, 283, 20152890. https://doi.org/10.1098/rspb.2015.2890

Smith, G. M., \& Coates, C. W. (1936). Cutaneous melanosis in lungfishes (LEPIDOSIRENIDAE). Biological Bulletin, 71, 282-285.

Suehiro, Y., Yasuda, A., Okuyama, T., Imada, H., Kuroyanagi, Y., Kubo, T., \& Takeuchi, H. (2009). Mass spectrometric map of neuropeptide expression and analysis of the gamma-prepro-tachykinin 
gene expression in the medaka (Oryzias latipes) brain. General and Comparative Endocrinology, 161, 138-145. https://doi.org/10.1016/j. ygcen.2008.12.001

Sugimoto, M., Nagamori, H., Yasui, H., \& Oshima, N. (1997). Regulation of melanophore responsiveness in the background-adapted medaka, Oryzias latipes: Change in the intracellular signaling system. Comparative Biochemistry and Physiology Part C: Pharmacology Toxicology and Endocrinology, 117, 259-265. https://doi.org/10.1016/ S0742-8413(97)00008-X

Sumpter, J. I., \& Lowry, A. J. (1984). The involvement of melanotrophins in physiological in the dogfish Scyliorhinus canicula colour change. General and Comparative Endocrinology, 367, 360-367.

Sundström, G., Dreborg, S., \& Larhammar, D. (2010). Concomitant duplications of opioid peptide and receptor genes before the origin of jawed vertebrates DeSalle R, ed. PLoS ONE, 5, e10512.

Takahashi, A., Amemiya, Y., Nozaki, M., Sower, S. A., Joss, J., Gorbman, A., \& Kawauchi, H. (1995). Isolation and characterization of melanotropins from lamprey pituitary glands. International Journal of Peptide and Protein Research, 46, 197-204. https://doi. org/10.1111/j.1399-3011.1995.tb00589.x

Takahashi, A., Amemiya, Y., Nozaki, M., Sower, S. A., \& Kawauchi, H. (2001). Evolutionary significance of proopiomelanocortin in agnatha and chondrichthyes. Comparative Biochemistry and Physiology Part B: Biochemistry and Molecular Biology, 129, 283-289. https://doi. org/10.1016/S1096-4959(01)00330-X

Takahashi, A., Tsuchiya, K., Yamanome, T., Amano, M., Yasuda, A., Yamamori, K., \& Kawauchi, H. (2004). Possible involvement of melanin-concentrating hormone in food intake in a teleost fish, barfin flounder. Peptides, 25, 1613-1622. https://doi.org/10.1016/j. peptides.2004.02.022

Takayama, Y., Wada, C., Kawauchi, H., \& Ono, M. (1989). Structures of two genes coding for melanin-concentrating hormone of chum salmon. Gene, 80, 65-73. https://doi.org/10.1016/0378-1119(89)90251-5

Tattersall, G. J., Eterovick, P. C., \& de Andrade, D. V. (2006). Tribute to R. G. Boutilier: Skin colour and body temperature changes in basking Bokermannohyla alvarengai (Bokermann 1956). Journal of Experimental Biology, 209, 1185-1196. https://doi.org/10.1242/jeb.02038

Umbers, K. D. L., Fabricant, S. A., Gawryszewski, F. M., Seago, A. E., \& Herberstein, M. E. (2014). Reversible colour change in Arthropoda. Biological Reviews of the Cambridge Philosophical Society, 89, 820-848. https://doi.org/10.1111/brv.12079

van der Salm, A. L., Metz, J. R., Wendelaar Bonga, S. E., \& Flik, G. (2005). Alpha-MSH, the melanocortin-1 receptor and background adaptation in the Mozambique tilapia, Oreochromis mossambicus. General and Comparative Endocrinology, 144, 140-149. https://doi.org/10.1016/j. ygcen.2005.05.009
Viale, A., Ortola, C., Hervieu, G., Furuta, M., Barbero, P., Steiner, D. F., ... Nahon, J. L. (1999). Cellular localization and role of prohormone convertases in the processing of pro-melanin concentrating hormone in mammals. Journal of Biological Chemistry, 274, 6536-6545. https:// doi.org/10.1074/jbc.274.10.6536

Visconti, M. A., \& de L. Castrucci, A. M. (1993). Melanotropin receptors in the cartilaginous fish, Potamotrygon reticulatus and in the lungfish, Lepidosiren paradoxa. Comp Biochem Physiol Part C Pharmacol Toxicol Endocrinol, 106, 523-528. https://doi. org/10.1016/0742-8413(93)90173-I

Wilkes, B., Hruby, V., Castrucci, A., Sherbrooke, W., \& Hadley, M. (1984). Synthesis of a cyclic melanotropic peptide exhibiting both melaninconcentrating and -dispersing activities. Science, 224, 1111-1113. https://doi.org/10.1126/science.6609433

Wollenberg, K. C., \& Measey, J. G. (2009). Why colour in subterranean vertebrates? Exploring the evolution of colour patterns in caecilian amphibians. Journal of Evolutionary Biology, 22, 1046-1056. https:// doi.org/10.1111/j.1420-9101.2009.01717.x

Zhang, C., Song, Y., Thompson, D. A., Madonna, M. A., Millhauser, G. L., Toro, S., ... Cone, R. D. (2010). Pineal-specific agouti protein regulates teleost background adaptation. Proceedings of the National Academy of Sciences, 107, 20164-20171. https://doi.org/10.1073/pnas.1014941107

Zhou, A., Bloomquist, B. T., \& Mains, R. E. (1993). The prohormone convertases PC1 and PC2 mediate distinct endoproteolytic cleavages in a strict temporal order during proopiomelanocortin biosynthetic processing. Journal of Biological Chemistry, 268, 1763-1769.

Zimova, M., Hackländer, K., Good, J. M., Melo-Ferreira, J., Alves, P. C., \& Mills, L. S. (2018). Function and underlying mechanisms of seasonal colour moulting in mammals and birds: What keeps them changing in a warming world? Biological Reviews, 93, 1478-1498.

\section{SUPPORTING INFORMATION}

Additional supporting information may be found online in the Supporting Information section at the end of the article.

How to cite this article: Bertolesi GE, Zhang JZ, McFarlane S. Plasticity for colour adaptation in vertebrates explained by the evolution of the genes pomc, pmch and pmchl. Pigment Cell Melanoma Res. 2019;32:510-527. https://doi.org/10.1111/ pcmr.12776 